\title{
Cell Lineage, Cell Death, and the Developmental Origin of Identified Serotonin- and Dopamine-Containing Neurons in the Leech
}

\author{
Duncan K. Stuart, Seth S. Blair, ${ }^{a}$ and David A. Weisblat ${ }^{\mathrm{b}}$ \\ Department of Molecular Biology, University of California, Berkeley, California 94720
}

The nervous system of the glossiphoniid leech includes segmentally iterated neurons that contain serotonin (5-HT) and dopamine. These have been investigated in Helobdella triserialis, Theromyzon rude, and Haementeria ghilianii. Five types of 5-HT neurons are identified by immunocytochemistry in the abdominal ganglia of the ventral nerve cord: the bilaterally paired Retzius, anteromedial, ventrolateral and dorsolateral neurons, and the unpaired posteromedial (pm) neuron. Three types of bilaterally paired dopamine neurons are identified by glyoxylic acid-induced fluorescence in the segmental body wall: MD, LD1, and LD2. Each left or right half of the segmental complement of the leech nervous system is known to develop from 6 distinct ectodermal primary blast cells $\left(n_{s}, n_{f}, 0, p, q_{s}\right.$, and $q_{f}$ ). To identify the blast cells of origin of the 5-HT and dopamine neurons, fluorescent cell lineage tracers were injected into the various precursors of the blast cells in early (stage 6) embryos. The embryos were then raised until their 5-HT and dopamine neurons could be scored (stage 11) for the presence or absence of lineage tracer. We find that the Retzius, anteromedial, and posteromedial 5-HT neurons are derived from the $n_{s}$ blast cell, while the ventrolateral and dorsolateral 5-HT neurons are derived

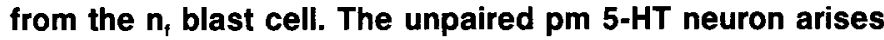
as one of a bilateral pair of neurons, of which one later dies. Whether the left or right pm neuron survives in any given ganglion is the consequence of some form of competitive interaction between cells derived from the left and right $\mathbf{n}$ primary blast cells, possibly between the left and right pm neurons themselves. We find that, of the dopamine neurons, the LD1 neuron is derived from the o blast cell, the LD2 neurons from the $p$ blast cell, and the MD neuron from one of the 2 kinds of $q$ blast cells. These results show that the 5-HT and dopamine neurons arise from 5 different primary blast cells in a highly determinate manner, and they support the view that cells of a similar phenotype need not be closely related in the developmental cell lineage tree.

Received June 9, 1986; revised Oct. 20, 1986; accepted Oct. 24, 1986.

This research was supportcd by National Institutcs of Hcalth NSRA NS07212, NIH Training Grant GM 07048 and by research grants NS 12818 and HD 17088 from the National Institutes of Health and BNS 79-12400 from the National Science Foundation, as well as by grants from the March of Dimes Birth Defects Foundation and the Rowland Foundation. We wish to thank Marty Shankland, Steven A. Torrence, and Gunther S. Stent for helpful comments on the manuscript.

Correspondence should be addressed to Duncan K. Stuart at the above address.

a Present address: Department of Zoology, University of Washington, Seattle, WA 98195.

b Present address: Department of Zoology, University of California, Berkeley, CA 94720 .

Copyright $@ 1987$ Society for Neuroscience $0270-6474 / 87 / 041107-16 \$ 02.00 / 0$
The eggs of glossiphoniid leeches undergo a series of stereotyped cell divisions that produces a set of identifiable blastomeres (Whitman, 1878; Schleip, 1936). By injecting various individual blastomeres of the early embryo with cell lineage tracers and observing the fate of their labeled descendants in the late embryo or juvenile leech, it has been shown that particular blastomeres give rise to specific portions of the mature nervous system (Weisblat et al., 1978, 1980a, b, 1984; Stent et al., 1982; Weisblat and Shankland, 1985).

The ccllular composition of the lecch ncrvous system is relatively simple, and many individual neurons have been identified in the adult leech by morphological, physiological, or biochemical criteria (Muller et al., 1981). The blastomeres from which some of these identified neurons arise have been established by combining the methods of lineage tracer injection with Lucifer yellow injection used for neuronal identification (Kramer and Weisblat, 1985). In this paper we report the results of similar experiments, designed to ascertain the blastomeres of origin of a set of histochemically identifiable, monoamine-containing neurons.

The leech CNS consists of the nonsegmental supraesophageal ganglion and the ventral nerve cord of 32 segmental ganglia, or neuromeres. The rostral 4 neuromeres fuse early in embryogenesis to form the subesophageal ganglion; the next 21 neuromeres remain unfused, linked via connective nerves, and are designated in rostrocaudal sequence as abdominal ganglia 1-21; and the caudal 7 neuromeres fuse to form the caudal ganglion. Each segmental ganglion contains about 400 neurons (Macagno, 1980), of which most, but not all, are present as bilaterally paired homologs. Moreover, for most neurons serial homologs can be identified from segment to segment. The PNS includes neurons whose cell bodies are located in the body wall. Many of these peripheral neurons are also bilaterally paired and segmentally iterated.

The leech nervous system includes 2 distinct types of monoamine-containing neurons. Neurons of 1 type contain serotonin (5-hydroxytryptamine, 5-HT) (Rude et al., 1969; Lent et al., 1979; Glover, 1987) and will be referred to as "serotonin (5HT) neurons." These neurons can be visualized by aldehydeinduced fluorescence (Ehinger et al., 1968; Marsden and Kerkut, 1969; Rude, 1969; Stuart et al., 1974; Stuart, 1981; Lent, 1982) or immunocytochemical techniques (Blair and Stuart, 1982; Stuart et al., 1983; Macagno et al., 1985; Leake et al., 1985; Glover, 1987). They are probably serotonergic, since in vitro some of them release 5-HT as a functional neurotransmitter (Henderson, 1983; Henderson et al., 1983). Neurons of the other type contain dopamine (Lent et al., 1983) and will be referred to as "dopamine neurons." As is the case for the 5-HT neurons, 
the dopamine neurons can be visualized by aldehyde-induced fluorescence. However, there is no direct physiological evidence that these neurons utilize dopamine as a neurotransmitter.

A tentative identification of the developmental origin of the monoamine-containing neurons was previously made in the glossiphoniid leech Helobdella triserialis by ablation of identified blastomeres (Blair, 1983). Following ablation in the early embryo of either one of the paired blastomeres designated as $\mathrm{N}$ teloblasts, 1 member of each pair of 5-HT neurons was missing in the abdominal ganglia (4-21) of the adult leech. Similarly, after ablation of one of the paired OP blastomeres or of one of the paired $Q$ teloblasts, 1 member of each pair of one or the other of 2 subsets of dopamine neurons was missing. Thus, these ablation experiments suggested that the 5-HT neurons normally arise from the $\mathrm{N}$ teloblast pair and that 1 subset of dopamine neurons normally arises from the OP blastomere pair and the other subset from the Q teloblast pair (Blair, 1983). However, the inference of this line of ancestry from ablation experiments is tentative, because a cell that is found to be missing after ablation of an identified blastomere may not normally arise as a descendant of that blastomere. Such a missing cell might normally arise as a descendant of another blastomere that requires, to express its normal fate, an inductive interaction with the ablated blastomere or with one of its descendants.

The present study examines the developmental origin of the monoamine-containing neurons in 3 species of glossiphoniid leech through the combined use of intracellularly injected cell lineage tracers, immunocytochemistry, and aldehyde-induced fluorescence. These findings confirm and extend the tentative conclusions of the previous ablation study. In addition, we report that the survival of one of the 5-HT neurons is dependent upon cell interactions within the developing nervous system.

Some of these results have been reported previously in preliminary form (Stuart, 1981; Blair and Stuart, 1982; Stuart et al., 1983).

\section{Materials and Methods.}

Animals. The developmental staging system used here for embryos of glossiphoniid leeches was previously described (Fernandez, 1980; Weisblat et al., 1980a; Stent et al., 1982; Kuwada and Kramer, 1983; Weisblat and Blair, 1984).

Embryos of Helobdella triserialis were obtained from our breeding colony in Berkeley (Weisblat et al., 1978). H. triserialis embryos were cultured at $25^{\circ} \mathrm{C}$ in antibiotic-supplemented embryo medium, changed daily (Weisblat et al., 1980a; Blair, 1982, 1983). This medium contains $4.8 \mathrm{~mm} \mathrm{NaCl}, 1.2 \mathrm{~mm} \mathrm{KCl}, 2.0 \mathrm{~mm} \mathrm{MgCl}_{2}, 8.0 \mathrm{~mm} \mathrm{CaCl}_{2}, 1.0 \mathrm{~mm}$ sodium maleate, $\mathrm{pH} 6.6$, supplemented with $50 \mu \mathrm{g} / \mathrm{ml}$ tetracycline hydrochloride, $40 \mu \mathrm{g} / \mathrm{ml}$ gentamycin sulfate, $100 \mathrm{units} / \mathrm{ml}$ potassium penicillin-G, and $100 \mu \mathrm{g} / \mathrm{ml}$ streptomycin sulfate. Upon reaching stage 11 , the embryos were transferred to antibiotic-supplemented spring water.

Embryos of Theromyzon rude were obtained from gravid adult specimens collected in the lakes of Golden Gate Park, San Francisco. The embryos were cultured at 18 or $12^{\circ} \mathrm{C}$ in the same medium as $H$. triserialis but without antibiotics (Torrence and Stuart, 1986).

Embryos of the giant leech Haementeria ghilianii were obtained from our breeding colony in Berkeley (Sawyer et al., 1981) maintained in 6.3 $\mathrm{mM} \mathrm{NaCl}, 0.7 \mathrm{mM} \mathrm{CaCl}_{2}, 0.7 \mathrm{mM} \mathrm{MgCl}$, and $0.05 \mathrm{~K}_{2} \mathrm{SO}_{4}$ buffered to pH 6.5 with $0.5 \mathrm{~mm}$ MES [2-( $N$-morpholino)ethanesulfonic acid]. The embryos were cultured at $27^{\circ} \mathrm{C}$ in an embryo medium containing 35.4 $\mathrm{mm} \mathrm{NaCl}, 2.0 \mathrm{~mm} \mathrm{CaCl}, 0.8 \mathrm{~mm} \mathrm{MgCl}_{2}$, and $0.5 \mathrm{~mm} \mathrm{KCl}$ buffered to pH 6.7 with $5.0 \mathrm{~mm}$ PIPES [piperazine- $N, N^{\prime}$-bis(2-ethanesulfonic acid)] (Kuwada and Kramer, 1983). This medium was changed daily and supplemented with tetracycline, penicillin, and streptomycin in the same concentrations as those used for the culture of $H$. triserialis embryos. During stages 6-8, the embryos were maintained in petri dishes (Pyrex glass bottom, Falcon plastic top) under a continuous flow of air mixed with nitrogen to reduce the oxygen tension to about one-third atmospheric. During stages 9 and 10, the embryos were kept under normal air.

Lineage tracers. Blastomeres were pressure-injected with cell lineage tracers, as described previously (Weisblat et al., 1978). For injection, the fluorescent tracers rhodamine dodecapeptide (RDP) (Weisblat et al., $1980 \mathrm{~b}$ ) or tetramethylrhodamine dextran amine (RDA) (Gimlich and Braun, 1985) were dissolved in $0.2 \mathrm{M} \mathrm{KCl}$ to a final concentration of 20 or $75 \mathrm{mg} / \mathrm{ml}$, respectivcly. To assist dircet visualization of the injection process, the lineage tracer solution also contained $10 \mathrm{mg} / \mathrm{ml}$ of Fast green FCF (Sigma).

All of the blastomeres could be identified uniquely at the time of injection except for the 2 sister $\mathrm{O} / \mathrm{P}$ teloblasts. These are equivalent at birth, but each produces a bandlet of cells that acquires a unique identity based on the relative position the bandlet happens to take in the germinal band (Shankland and Weisblat, 1984; Weisblat and Blair, 1984). We determined which of the 2 possible bandlets was labeled with lineage tracer by observing which of the 2 characteristic groups of cells later arose containing tracer.

Blastomere ablation. Blastomeres were ablated by injection of a 10 $\mathrm{mg} / \mathrm{ml}$ solution of DNase I (Sigma type III) in $0.15 \mathrm{M} \mathrm{NaCl}$ (Blair, 1982) to which $6 \mathrm{mg} / \mathrm{ml}$ of Fast green FCF had been added.

5-HT immunofluorescence. Antisera against 5-HT were used to visualize embryonic 5-HT neurons in nerve cords still attached to the germinal plate of $H$. ghilianii and $T$. rude and in the isolated nerve cords of $H$. triserialis. The large $H$. ghilianii and $T$. rude embryos were first pinned out flat in Haementeria Ringer solution (Kramer and Goldman, 1981) containing $80 \mathrm{~mm}$ chlorobutanol (Sigma). A dorsal, longitudinal incision was made, and the yolk was removed (Kuwada and Kramer, 1983; Torrence and Stuart, 1986; D. Stuart and J. Glover, unpublished observations). The smaller $H$. triserialis embryos were relaxed at $4^{\circ} \mathrm{C}$ in culture medium (or spring water) containing $80 \mathrm{~mm}$ chlorobutanol and then fixed before dissection.

All embryos were fixed for $18-24 \mathrm{hr}$ at $4^{\circ} \mathrm{C}$. with a $40 \mathrm{mg} / \mathrm{ml}$ paraformaldehyde solution in $50 \mathrm{~mm}$ HEPES- $\mathrm{NaOH}$ buffer, $\mathrm{pH} 7.4$, containing $10 \mu \mathrm{g} / \mathrm{ml}$ of the DNA-specific fluorescent dye Hoechst 33258 (Aldrich). In some cases the embryos were preincubated for $2 \mathrm{hr}$ before fixation in culture medium or spring water to which 5-HT (as the creatinine sulfate complex, Sigma) had been just added to a final concentration of $10^{-4}$ or $10^{-3} \mathrm{M}$. Such preincubation selectively increases the immunoreactivity of the 5-HT neurons (D. Stuart and J. Glover, unpublished observations). After fixation, the embryos were rinsed several times in 50 mм HEPES-NaOH buffered saline, pH 7.4, containing 1 $\mathrm{mg} / \mathrm{ml}$ sodium azide (HBS) and stored at $4^{\circ} \mathrm{C}$ for up to several weeks.

To isolate the nerve cord from the small $(0.8 \mathrm{~mm}$ long) $H$. triserialis embryos, a dorsal longitudinal incision was made in the fixed embryo with a sharpened insect pin $(000)$ attached to a wooden stick and inserted inside the body wall and rubbed against a second pin held just outside the wall. The sides were then pinned to the dish using fine 0.01 in. $(0.025 \mathrm{~mm})$ tungsten wire, and the entire nerve cord was removed with the sharpened insect pin.

The 5-HT neurons were labeled with rabbit antisera against 5-HT coupled via formaldehyde to BSA (Steinbusch et al., 1978). The labeling was carried out at $4^{\circ} \mathrm{C}$ in a $0.3 \mathrm{ml}$ conical sample cup (Sarstedt, No. 73.640 , or Fisher, No. 02-544-65) on a rotating shaker. Nerve cords, either isolated or attached to the body wall, were placed in HBS containing $2 \mathrm{mg} / \mathrm{ml}$ Triton X-100, $30 \mathrm{mg} / \mathrm{ml}$ goat serum, $100 \mathrm{mg} / \mathrm{ml}$ BSA and rabbit anti-5-HT antisera (Immunonuclear, lot no. 29311, diluted 1:500; lot no 40122, diluted 1:200; or lot no. 8431011, diluted 1:500) and incubated for $12-20 \mathrm{hr}$. The nerve cords were then rinsed for several hours in the same solution without antiserum (rinse solution) and incubated for 12-20 hr in rinse solution containing fluorescein- or rhodamine-conjugated goat anti-rabbit antibodies (Cappel, no. 1212-0081 or 2212-0081) diluted 1:100, 1:200, or 1:400. The fluorescently labeled nerve cords were then rinsed, first with rinse solution and then with HBS.

Whole-mounts. Antibody-labeled specimens were cleared for at least $30 \mathrm{~min}$ in a solution of $80 \%$ glycerol and $20 \% 0.1 \mathrm{~m}$ Tris-CHl, $\mathrm{pH} 9.0$, containing $40 \mathrm{mg} / \mathrm{ml} n$-propyl gallate (Giloh and Sedat, 1982). (The $n$-propyl gallate should be dissolved first in the glycerol.) They were then mounted between 2 coverslips with the edges sealed with Fluoromount (Gurr). Propyl gallate reduces photobleaching of the fluorescein and rhodamine dyes. Specimens treated in this manner have been maintained for several years at $-20^{\circ} \mathrm{C}$ without noticeable loss of fluorescence.

Sections. Isolated $H$. triserialis nerve cords were fixed a second time 
with paraformaldehyde as above, dehydrated in a short, graded series of methacrylate monomer (charcoal-filtered to reduce background fluorescence), positioned within a small transparent embedding mold, and embedded in glycol methacrylate (Sorvall Embedding Medium). This procedure avoided alcohol, which had an adverse effect on staining with the Hoechst 33258 dye. Some loss of antibody and tracer fluorescence (especially that of fluoresceinated molecules) was observed during embedding, presumably because of free radicals generated by the polymerization catalyst.

The embedded nerve cords were sectioned transversely ( $3 \mu \mathrm{m}$ thick) with glass knives on a Sorvall JB-4 Microtome. Each section was transferred to a drop of $10 \mathrm{mM} \mathrm{NH}_{4} \mathrm{OH}$ on a gelatin-coated glass slide, dried, and mounted under a coverslip with the glycerol/propyl gallate solution described above.

Aldehyde-induced dopamine and 5-HT fluorescence. Dopamine neurons were visualized by means of the glyoxylic acid-induced fluorescence technique (Lindvall and Bjorklund, 1974; de la Torre and Surgeon, 1976), modified for unsectioned tissue (Stuart, 1981; Lent, 1982). Living, midstage $11 \mathrm{H}$. triserialis embryos were relaxed and opened by a dorsal incision as described above for fixed embryos. The yolk was removed and the nerve cord left in place.

To induce dopamine histofluorescence, the preparation was placed on a glass coverslip and exposed for $1-2 \mathrm{~min}$ to $10 \mathrm{mg} / \mathrm{ml}$ glyoxylic acid in $0.2 \mathrm{M}$ sucrose and $0.256 \mathrm{M}$ potassium phosphate buffer, $\mathrm{pH} 7.4$, at $4^{\circ} \mathrm{C}$. The preparation was then dried on the coverslip under a stream of dry air, covered with a drop of mineral oil, healed for about 4 min at $95^{\circ} \mathrm{C}$, and finally mounted in Fluoromount. The optimal duration of heating varied for different preparations. This treatment results in blue fluorescence of dopamine neurons. This treatment also results in yellow fluorescence of 5-HT neurons, but in leech embryos glyoxylic acidinduced 5-HT fluorescence is neither as sensitive nor as reliable an assay as the immunofluorescence assay, and it was used here only to identify the distribution of 5-HT neurons in the adult leech.

Visualization. Preparations were examined by phase-contrast and epifluorescence microscopy. Zeiss filter sets $487705,487701,487715$, and 487717 were used to visualize the glyoxylic acid-induced fluorescence and the fluorescence due to Hoechst, rhodamine, and fluorescein dyes, respectively. Images were photographed with Kodak Technical Pan film 2415 (Figs. 2, 10), Plus X (Figs. 5, 6, 8), Tri-X (Fig. 7), or VR 400 (Fig. 4) film. Micrographs showing 2 different labels in the same specimen (Figs. $5 B, 6 B, 8 E$ ) were made as double exposures. Figure 10 was printed directly from the negative; for the other micrographs, interpositives were made from the original negatives on Polaroid Type $55 \mathrm{film}$. The figures were then printed from the interpositives. In the resulting negative image, fluorescence is rendered dark against a light background.

\section{Results}

\section{Development of the ectoderm}

In glossiphoniid leeches the ectoderm, the main source of nervous and epidermal tissues, is derived from 2 bilaterally paired blastomeres designated as NOPQ. During stage 7 each of the paired NOPQ blastomeres divides to form an $\mathrm{N}$ teloblast and an OPQ blastomere. The OPQ blastomere then divides to form a $Q$ teloblast and OP blastomere, which, in turn, divides symmetrically to produce two O/P sister teloblasts. Each ectodermal teloblast buds off several dozen, much smaller primary blast cells, which leave their mother cell in discrete columns, or bandlets. The four ectodermal bandlets, lying in order $n, o, p$, and $\mathrm{q}$, together with an underlying $\mathrm{m}$ bandlet of blast cells derived from the paired mesodermal precursor teloblast $M$, merge on either side of the midline to form a hemilateral germinal band (Fig. 1).

Left and right germinal bands move over the surface of the embryo, and during stage 7 their anterior ends, comprising the first-born blast cells, converge at the site of the future head. During stage 8 the hemilateral germinal bands join in parallel along the ventral midline of the embryo to form the germinal plate. On either side of the germinal plate the 4 ectodermal bandlets then lie with the $\mathrm{n}$ bandlet most medial and the $\mathrm{q}$

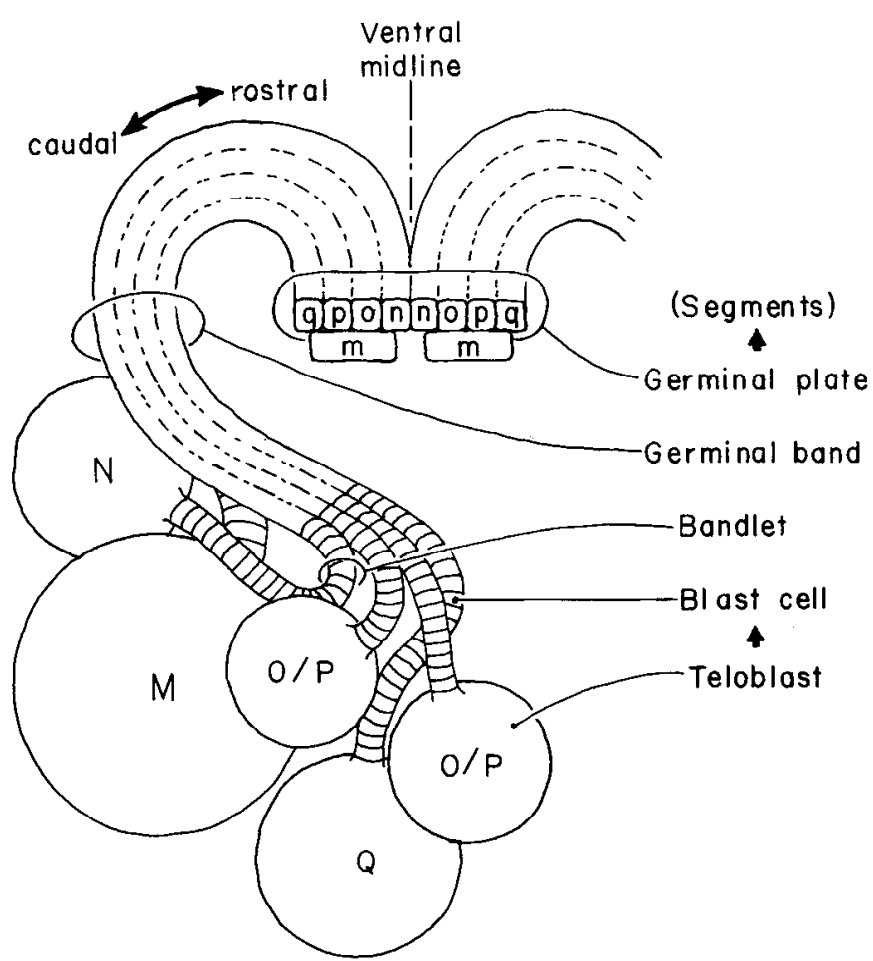

Figure 1. Schematic summary of early stage 8 development in $H$. triserialis showing the positions of the teloblasts and blast cell bandlets in the left germinal band and germinal plate. Five pairs of teloblasts, the mesodermal $\mathrm{M}$ and ectodermal $\mathrm{N}, \mathrm{O} / \mathrm{P}, \mathrm{O} / \mathrm{P}$, and $\mathrm{Q}$ pairs are formed from the D blastomere. Each teloblast divides repeatedly to form a chain, or bandlet, of much smaller primary blast cells. The 5 bandlets on one side of the embryo join together to form a germinal band that moves over the surface of the embryo to join with the opposite germinal band to form the germinal plate. In carly stage 8 , only the germinal plate destined to contribute to the anterior end of the leech has been formed.

bandlet most lateral and with the $m$ bandlet lying underneath them (Fig. 1).

In subsequent development, the primary blast cells from each $\mathrm{m}, \mathrm{n}, \mathrm{o}, \mathrm{p}$, or $\mathrm{q}$ bandlet (designated by the same letter as their bandlet of origin) proliferate to produce a characteristic cell pattern made up of segmentally iterated complements of progeny that ultimately produce the segmental tissues of the mature animal. Nearly identical cell patterns are produced by corresponding bandlets in $H$. triserialis and $T$. rude (Weisblat et al., 1984; Weisblat and Shankland, 1985; Torrence and Stuart, 1986) and in the ventral nerve cord of $H$. ghilianii (Kramer and Weisblat, 1985); the body wall of $H$. ghilianii has not been examined in detail.

A segment is defined as the iterated anatomical unit containing an abdominal ganglion (or the corresponding neuromere of the fused subesophageal or caudal ganglion) at the midpoint of its longitudinal axis, and a hemisegment is either the left or right half of a segment. In the $\mathrm{m}, \mathrm{o}$, and $\mathrm{p}$ bandlets, one $\mathrm{m}, \mathrm{o}$, or $\mathrm{p}$ primary blast cell generates 1 hemisegmental complement of progeny, whereas in the $n$ and $q$ bandlets, 2 adjacent $n$ or $q$ primary blast cells, designated respectively as $n_{f}$ and $n_{s}$ or $q_{f}$ and $\mathrm{q}_{\mathrm{s}}$, generate 1 complete hemisegmental complement (Zackson, 1984; Weisblat and Shankland, 1985). Moreover, parts of a hemisegmental complement derived from 1 primary blast cell are interdigitated with the clones of its adjacent sister blast cells. 


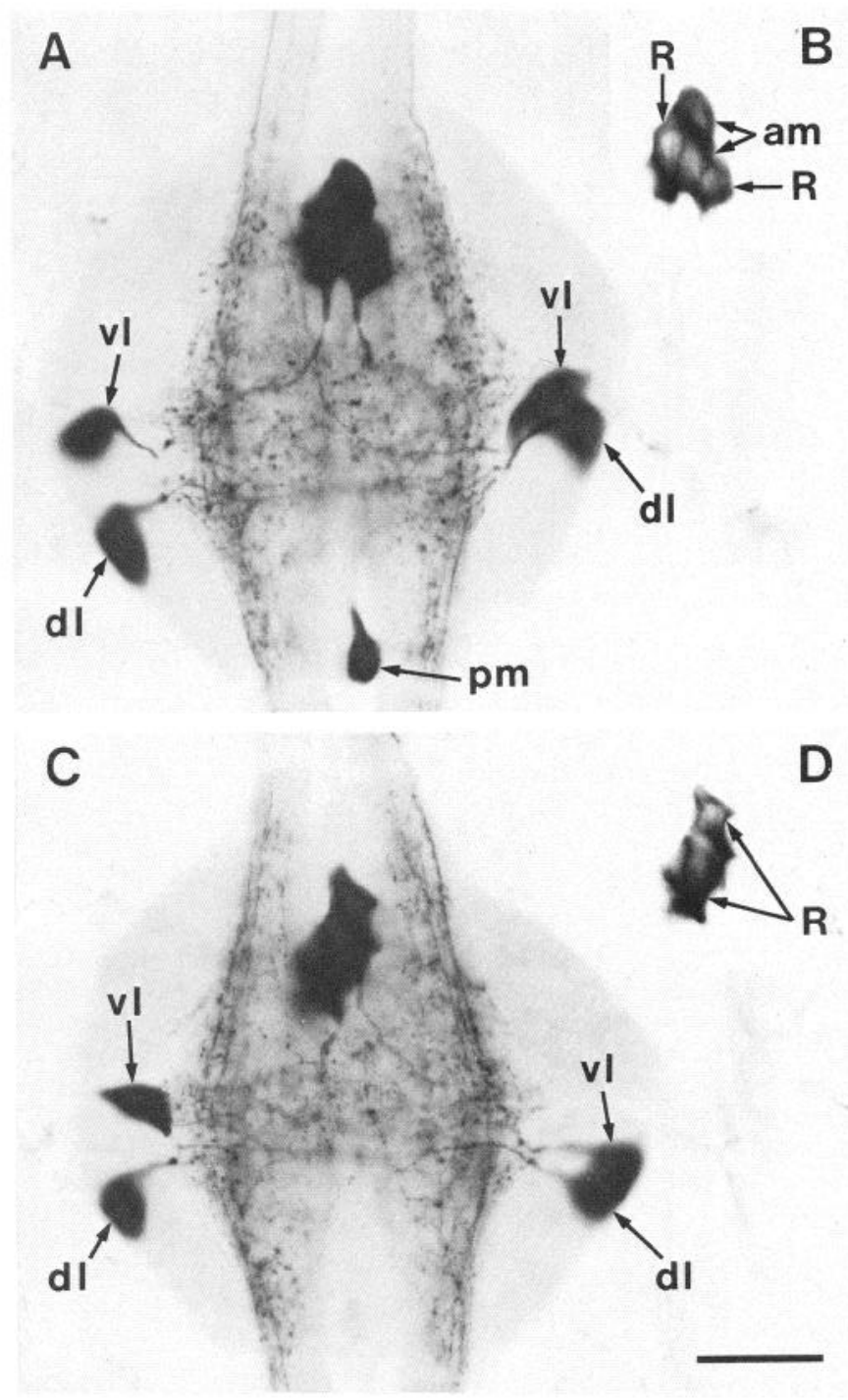

Figure 2. Types of 5-HT neurons in fully formed abdominal ganglia. Two patterns of 5-HT neurons are shown in these negative fluorescence micrographs of 2 abdominal ganglia. The ganglia are from a wholemounted, late-stage $11 \mathrm{~T}$. rude embryo stained with 5-HT antibody. $A$, Abdominal ganglion 3, representing the pattern in the first 3 abdominal ganglia. All 5 types of 5-HT neurons are present: the anteromedial pair $(a m$, see inset $B)$, the giant Retzius pair $(R$, see inset $B)$, the ventrolateral pair $(v l)$, the dorsolateral pair $(d l)$, and the unpaired posteromedial neuron $(p m) . B$, Retzius and anteromedial neurons in the same ganglion shown in $A$, printed to reveal the individual cell bodies. $C$, Abdominal ganglion 10 , representing the pattern of most midbody abdominal ganglia. Only 3 pairs of 5-HT neurons are present: Retzius, ventrolateral, and dorsolateral. $D$, Retzius neurons in the ganglion shown in $C$. Anterior is uppermost here and in all subsequent figures unless noted. Scale bar, $25 \mu \mathrm{m}$.

Thus, 1 blast cell clone may be spread over 2 or more segments (Weisblat and Shankland, 1985; D. K. Stuart and S. Zackson, unpublished observations).

Concomitantly with blast cell proliferation there occurs a circumferential expansion of the germinal plate over the surface of the embryo during stages 9 and 10 . Eventually, left and right leading edges of the germinal plate meet and fuse on the future dorsal midline, closing the leech body at the end of stage 10 . By this time, most of the neurons of the ventral nerve cord have achieved their definitive positions and established a pattern of axonal outgrowth (Kramer and Kuwada, 1983). Morphological, biochemical, and behavioral maturation of the embryo continues during stage 11, at the conclusion of which the juvenile leech is ready to take its first meal.

\section{Distribution of 5-HT neurons}

5-HT immunofluorescence reliably identifies the stereotyped complement of 5-HT neurons in the intact nerve cord of stage 9-11 embryos of glossiphoniid leeches, whereas glyoxylic acidinduced fluorescence reliably identifies the 5-HT neurons in juvenile and adult nerve cords. To facilitate the discussion of the actual distribution of the 5-HT neurons in glossiphoniid adults and stage 11 embryos, we define the "basic set" of 9 identified neurons, consisting of 5 types. Some or all members of the basic set are found in each abdominal ganglion, and in each neuromere in the fused subesophageal or caudal ganglia. The basic set consists of the pair of giant Retzius (R) neurons, 3 pairs of smaller anteromedial $(\mathrm{am})$, ventrolateral $(\mathrm{vl})$, and dorsolateral (dl) neurons, and 1 unpaired posteromedial (pm) neuron (Fig. $2, A, B$ ). In $H$. ghilianii and $H$. triserialis the entire basic set is present in the anteriormost 3 abdominal ganglia (13 ), while all other abdominal ganglia (4-21) lack the anteromedial pair. In addition, the posteriormost 14 abdominal ganglia (8-21) lack the unpaired pm neuron (Fig. 2, $C, D$ ). In adults, abdominal ganglia 5 and 6 , lying in the genital segments, lack the dorsolateral neuron pair, but in stage 11 embryos, the dorsolateral neurons are often visible in these two ganglia, although staining faintly. The distribution of 5-HT neurons is summarized in Figure 3. Some minor differences in the distribution of 5-HT neurons in $T$. rude and the distribution of 5-HT neurons found in each neuromere of the subesophageal and caudal ganglia will be described elsewhere (D. Stuart and J. Glover, unpublished observations). Our nomenclature of 5-HT neurons differs somewhat from that used for the hirudid leeches, in which the homologous anteromedial and pm neurons have been designated as "extra" and "unpaired medial" neurons (Lent, 1981) and the ventrolateral and dorsolateral neurons have in some cases been designated as "61" and " 21 " (Nusbaum, 1986; Nusbaum and Kristan, 1986).

\section{Bandlet of origin of 5-HT neurons}

To ascertain the developmental origin of the 5-HT neurons, specific blast cell bandlets were labeled with the cell lineage tracer RDA by injecting it into identified blastomeres of stage $6 \mathrm{H}$. triserialis embryos. The embryos were raised to stage 11 , the 5-HT neurons were labeled with anti-5-HT antibody, and the nerve cords were serially sectioned (Fig. 4). In these sections the 5-HT neurons could be clearly identified with respect to both the fluorescein label of the 5-HT immunofluorescence (Fig. $4 B$ ) and the rhodamine label of the RDA lineage tracer (Fig. $4 C$ ). The results (Table 1) showed that in the 2 embryos in which an $\mathrm{n}$ bandlet was labeled, all 98 ipsilateral 5-HT neurons that could be scored contained the lineage tracer. Moreover, in the 2 embryos in which the o, p, and $\mathrm{q}$ bandlets were simultaneously labeled by injection of the OPQ blastomere, none of the 107 ipsilateral 5-HT neurons that were examined contained the tracer.

The 5-HT neurons scored in sections and in similar experiments utilizing whole-mounts comprised neurons, including the anteromedial pair, from all ganglia along the entire length of the nerve cord, including the subesophageal and caudal ganglia. 


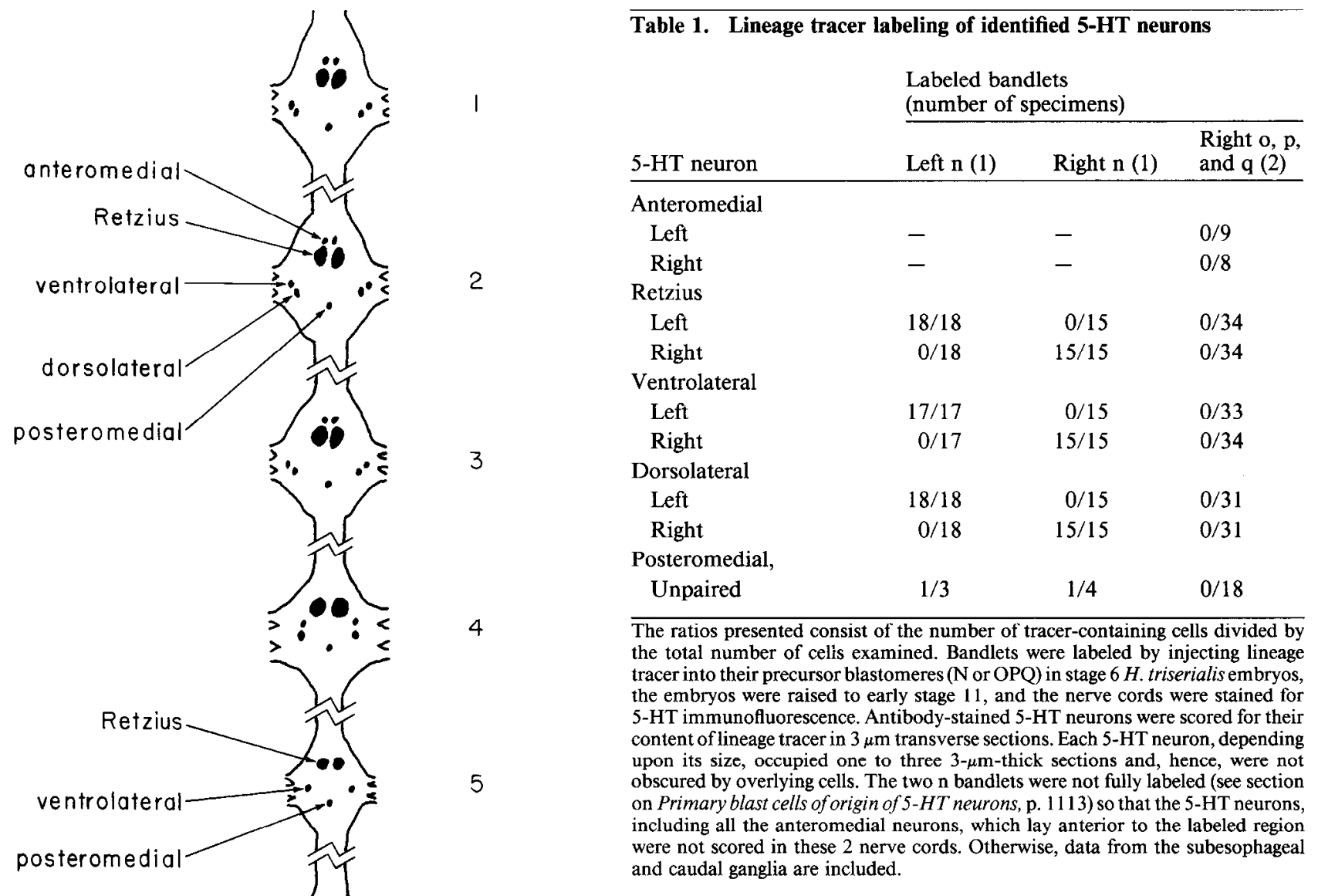

6

7

8

Figure 3. Schematic representation of the distribution of 5-HT neurons, as visualized by glyoxylic acid-induced fluorescence in abdominal ganglia of adult $H$. ghilianii. The number identifying each ganglion is shown along the right side of the figure. Most of the length of the connective nerves between ganglia is omitted. There are 4 distinct 5-HT cell patterns, each found in a specific subset of the ganglia. Ganglia 13 share a common pattern, as do ganglia 4 and 7 , ganglia 5 and 6 ganglia 8-21. All 5 types of 5-HT neurons-the anteromedial, Retzius, ventrolateral, dorsolateral, and unpaired posteromedial-are present in
We infer that, in $H$. triserialis, the entire set of 5-HT neurons of the ventral nerve cord is derived from the pair of $n$ bandlets, as suggested by earlier ablation experiments (Blair, 1983).

To extend this conclusion to another glossiphoniid leech species, a similar experiment was performed with an $H$. ghilianii embryo in which the right $\mathbf{n}$ bandlet was labeled with the lineage tracer RDP. The 5-HT immunofluorescence was developed at midstage 10 , and the nerve cord of this specimen was examined in whole-mount. We found that of the identifiable 5-HT neurons all 83 in the RDP-labeled right half of the nerve cord contained the tracer, none of the 80 in the left half contained tracer, and 4 of the 10 unpaired pm neurons contained tracer (discussed in next section). All the 5-HT neurons of the abdominal ganglia were scored, as well as 10 in the ipsilateral subesophageal ganglion, 7 in the ipsilateral caudal ganglion, as well as 3 unpaired pm neurons in the caudal ganglion. Thus, the 5-HT neurons of the $H$. ghilianii ventral nerve cord, just as those of $H$. triserialis, are derived from the pair of $\mathbf{n}$ bandlets.

Origin of the unpaired posteromedial 5-HT neuron

Experiments in which the distribution of lineage tracer was scored in whole-mounted $H$. triserialis nerve cords yielded another clear result: of 42 unpaired pm 5-HT neurons scored in 6 embryos with a labeled $\mathbf{n}$ bandlet, only 23 contained the

$\leftarrow$

abdominal ganglia 1-3; the rest of the ganglia lack the anteromedial neurons. The dorsolateral neurons are absent from abdominal ganglia 5 and 6 , although they are often present in these ganglia in stage 11 embryos. Finally, abdominal ganglia 8-21 lack the unpaired posteromedial neuron. Scale bar, $500 \mu \mathrm{m}$. 


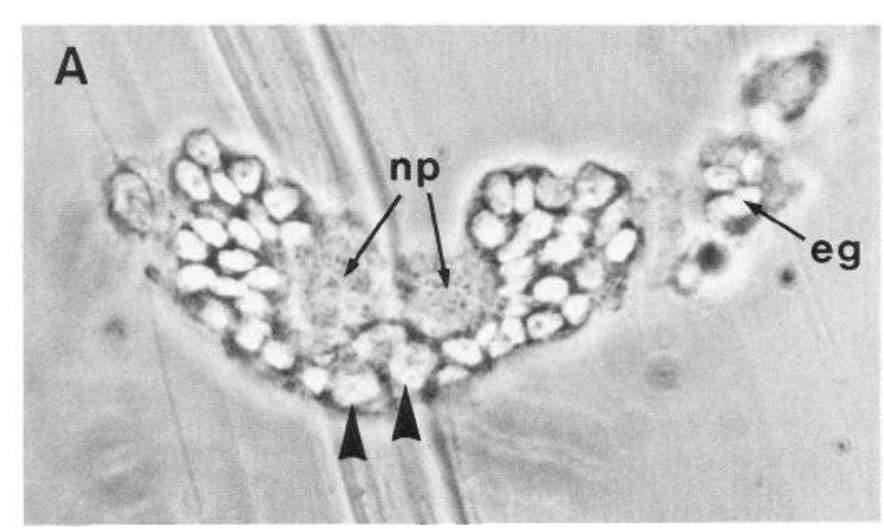

B
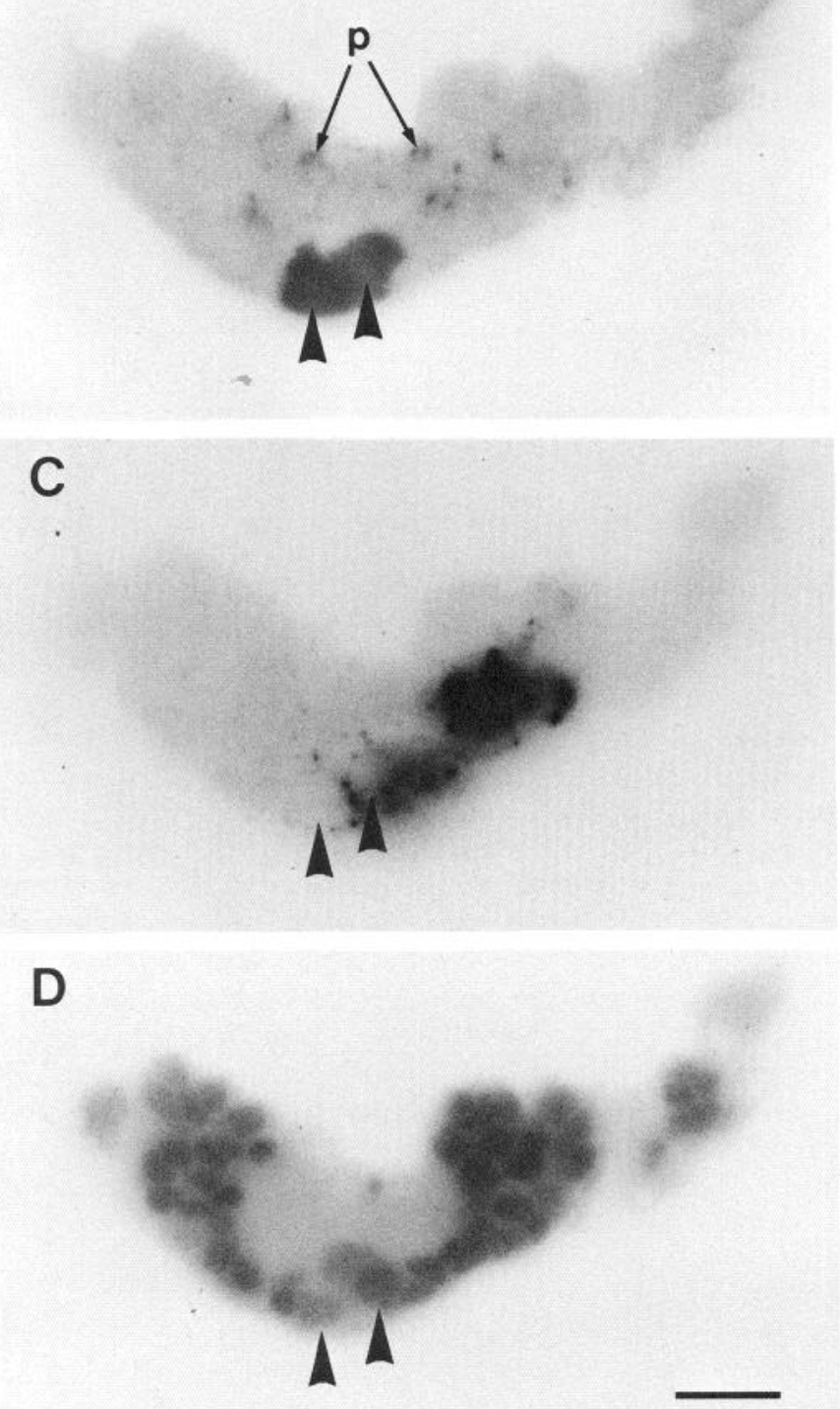

Figure 4. Derivation of the Retzius neuron from the ipsilateral $\mathrm{n}$ bandlet. Two Retzius neurons are evident in this transverse, $3 \mu \mathrm{m}$ section through abdominal ganglion 8 of an $H$. triserialis embryonic nerve cord. The left $\mathrm{n}$ bandlet of the embryo had been labeled by injecting the left $\mathrm{N}$ teloblast at stage 6 with RDA cell lineage tracer. The embryo was raised to midstage 11 , when the nerve cord was dissected from the body wall, stained with 5-HT antibody and the DNA-specific Hoechst dye, and sectioned. In each panel, the lower pair of arrowheads points to nuclei of the Retzius neurons. $A$, Phase-contrast micrograph of the tracer. Furthermore, the segmental distribution of tracer-labeled and unlabeled 5-HT pm neurons appeared to vary randomly from specimen to specimen (Table 2). Similar results were observed in sectioned nerve cords (Table 1). The unpaired pm neuron was never found to be labeled after the o, p, and q bandlets had been simultaneously labeled, either in whole-mount (none of 42 neurons was labeled in 6 embryos) or in sections (Table 1). Thus, the unpaired pm neurons that were unlabeled in embryos in which one $\mathrm{n}$ bandlet had been labeled are apparently derived from the contralateral, unlabeled $\mathbf{n}$ bandlet. The variability of the pattern of labeling further suggests that for any given segment it is not predetermined which $\mathrm{n}$ bandlet will give rise to the unpaired pm neuron.

Examination of the 5-HT neurons at an earlier stage of development, at the end of stage 9, reveals that a pair of pm 5-HT neurons is initially present in each of abdominal ganglia 1-7 (Fig. 5). In late stage $9 \mathrm{H}$. triserialis embryos in which an $\mathrm{n}$ bandlet had been labeled with lineage tracer, the pm neuron on the labeled side contains tracer (not illustrated). When first identifiable by 5-HT immunofluorescence, both pm neurons in a ganglion of $H$. ghilianii have already grown a primary axon (not illustrated) and can be visualized for a period of only a day or so. One member of the pm neuron pair begins to show less intense immunofluorescence than the other soon after both neurons have become identifiable. Pyknosis of its nucleus, visualized with the DNA-specific Hoechst dye, reveals that the less intensely immunofluorescent neuron is dying (Fig. 6). No correlation was observed between which member of the pm neuron pair dies and its anteroposterior or mediolateral position relative to the surviving neuron ( 27 pairs of pm neurons examined in 6 different embryos). After the dying neuron's loss of 5-HT immunofluorescence, its pyknotic nucleus often moves to a more superficial (ventral) position in the ganglion. The dying neuron appears to be engulfed by a glial cell, which, during the death of the pm neuron, takes on a faint 5-HT immunofluorescence, suggesting that the glial cell has taken up 5-HT from the dying neuron. Thus, the unpaired pm 5-HT neuron of the adult leech ganglion is the lone survivor of what was originally a bilateral cell pair. No such transient appearance of pm 5-HT neurons was observed in abdominal ganglia $8-21$, which normally lack a pm 5-HT neuron altogether.

Is the decision whether the left or the right $\mathrm{n}$ bandlet gives rise to the surviving unpaired pm neuron in a given segment based on an interaction between cells derived from these 2 bandlets or between both bandlets and cells derived from other sources? To answer this question, one of the two $\mathrm{N}$ teloblasts was ablated in stage 6 embryos by injecting it with DNase I (Blair, 1982) before it had generated more than a few of the primary blast cells of its $\mathrm{n}$ bandlet. The operated embryos were raised to midstage 11 , at which time they were fixed and their nerve cords removed and stained with 5-HT immunofluorescence.

ganglion showing the cortical cell bodies surrounding the central neuropile $(n p)$. Extraganglionic tissue $(e g)$ is present in the apparent right side of the section. $B-D$, Micrographs are negative images of the 3 fluorescent labels. $B, 5-\mathrm{HT}$ immunofluorescence. Both of the Retzius neurons are stained, as are 5-HT-containing processes $(p)$ in the neuropile. $C$, RDA lineage tracer fluorescence. Of the 2 Retzius neurons, only the left (apparent right) fluoresces along with other cell bodies (not containing 5-HT) ipsilateral to the injected $\mathrm{n}$ bandlet. $D$, DNA-specific Hoechst dye fluorescence. Dorsal is uppermost. Scale bar, $10 \mu \mathrm{m}$. 
Table 2. Lineage tracer labeling of unpaired posteromedial 5-HT neuron

\begin{tabular}{llllllll}
\multicolumn{7}{c}{ Abdominal ganglion number } \\
\cline { 2 - 8 } Specimen & 1 & 2 & 3 & 4 & 5 & 6 & 7 \\
\hline 1 & + & - & - & + & + & - & - \\
2 & + & - & + & + & - & - & + \\
3 & + & + & + & - & - & + & + \\
4 & - & + & - & + & - & + & - \\
5 & + & - & + & + & - & - & - \\
6 & + & - & + & + & + & + & -
\end{tabular}

The table indicates the presence $(+)$ or absence $(-)$ of lineage tracer label in the unpaired posteromedial 5-HT neurons of abdominal ganglia 1-7 in 6 different stage $11 \mathrm{H}$. triserialis embryos. The left $\mathrm{n}$ bandlet was labeled with the lineage tracer RDP.

As Blair (1983) showed previously for abdominal ganglia 421 , when formation of onc of the two $\mathrm{n}$ bandlets is abortcd by ablation of its parent $\mathrm{N}$ teloblast, 1 member of each pair of 5-HT neurons fails to develop. If the normal death of one of the initially paired $\mathrm{pm} 5$-HT neurons and survival of the other were due to an interaction between the two $n$ bandlets or their progeny, then elimination of one of the two $n$ bandlets by ablation of its precursor teloblast should for each of abdominal ganglia 1-7 result in either the presence of a pm neuron, derived from the remaining $\mathrm{n}$ bandlet, or the complete absence of a $\mathrm{pm}$ neuron. By contrast, if death and survival of the paired pm neurons were controlled by cells other than those derived from the contralateral $n$ bandlet, then after ablation of one $n$ bandlet the surviving $\mathrm{n}$ bandlet should produce its normal number of unpaired pm 5-HT neurons, namely, those in only about half of the abdominal ganglia 1-7.

In embryos in which only one $\mathbf{n}$ bandlet was present, it was not always possible to identify individually the 5-HT neurons formed because neurons arising from that lone $\mathrm{n}$ bandlet often abandoned their normal positions and crossed the midline to a comparable position on the deficient side of the nerve cord (Blair and Weisblat, 1982). Furthermore, in such deficient embryos adjacent ganglia sometimes fuse. However, if under these circumstances 1 unpaired pm neuron were still present in each of abdominal ganglia 1-7, then abdominal ganglia 1-3 should contain five 5-HT neurons each and abdominal ganglia 4-7 four 5-HT neurons each, making a total of 31 5-HT neurons in abdominal ganglia $1-7$. By contrast, if half of abdominal ganglia 1-7 lacked their unpaired pm neuron in such embryos, then this set of ganglia should contain an average total of only $27.55-\mathrm{HT}$ neurons (either four or five 5-HT neurons in each of abdominal ganglia 1-3 and either three or four in each of abdominal ganglia 4-7).

Of $20 \mathrm{H}$. triserialis embryos in which one $\mathbf{n}$ bandlet was absent due to ablation of its precursor teloblast, 6 survived to midstage 11 and were scored for the presence of 5-HT neurons. Abdominal ganglia 1-7 contained a total of 31 5-HT neurons in 4 of these specimens (Fig. 7) and $305-\mathrm{HT}$ neurons in the other 2 specimens (Table 3). Furthermore, the 5-HT neurons were distributed as expected among segmental ganglia $1-3$ and $4-7$. In the 2 specimens with only 30 neurons, ganglia 5 and 6 in the genital segments were fused, and between them contained only 7 , rather than $8,5-\mathrm{HT}$ neurons. The one missing neuron is likely to be one of the paired dorsolateral 5-HT neurons, which, at late stage 11, show a much less intense immunofluorescence in
Table 3. Development of 5-HT neurons when 1 of the $2 \mathrm{n}$ bandlets is absent

\begin{tabular}{|c|c|c|c|c|c|c|c|}
\hline \multirow[b]{2}{*}{ Specimen } & \multicolumn{7}{|c|}{ Abdominal ganglion number } \\
\hline & 1 & 2 & 3 & 4 & 5 & 7 & $1-7$ \\
\hline 1 & 5 & 5 & 5 & 4 & 4 & 4 & 31 \\
\hline 2 & 5 & 5 & 5 & 4 & 4 & 4 & 31 \\
\hline 3 & 5 & 5 & $\ldots .(9)$ & $\ldots$ & 44 & 4 & 31 \\
\hline 4 & 5 & 5 & 5 & $\ldots$ & $\ldots(16)$ & $-\ldots$ & 31 \\
\hline 5 & 5 & 5 & 5 & 4 & $-(7)$ & 4 & 30 \\
\hline 6 & 5 &..$(10)$ & & 4 & - (7) $\ldots$ & 4 & 30 \\
\hline
\end{tabular}

The entries show the number of 5-HT neurons that developed in each of abdominal ganglia 1-7 in 6 different stage $11 \mathrm{H}$, triserialis embryos in which only $1 \mathrm{n}$ bandlet had formed due to ablation of 1 of the 2 parental $\mathrm{N}$ teloblasts at early stage 6 . Wherever fusion of adjacent ganglia prevented counts of 5-HT neurons in individual ganglia, the total number of 5-HT neurons in the fused ganglia is shown in parenthesis. The total number of 5-HT neurons present in all 7 ganglia is indicated in the last column. Normal embryos with two $n$ bandlets present have $95-\mathrm{HT}$ neurons in each of abdominal ganglia $1-3$ and 7 in each of abdominal ganglia 4 7 for a total of $555-\mathrm{HT}$ neurons.

abdominal ganglia 5 and 6 than do the other 5-HT neurons (Stuart et al., 1983; Glover, 1987; D. Stuart and J. Glover, unpublished observations). For comparison, the next 7 abdominal ganglia (8-14), which normally lack the unpaired pm neuron and contain only 3 pairs of 5-HT neurons, were examined in these same 6 embryos and were all found to contain the expected $(7 \times 3=21) 5-\mathrm{HT}$ neurons. These results indicate that 1 unpaired pm 5-HT neuron is always present in each of the abdominal ganglia 1-7 after the formation of one of the two $n$ bandlets is aborted by ablation of its parent $\mathrm{N}$ teloblast. This finding suggests that in normal development the death in these ganglia of 1 member of the pm neuron pair is due to an interaction between cells derived from the left and right $n$ bandlets.

It was previously reported that, contrary to the present finding, in embryos lacking one $\mathrm{n}$ bandlet only half the normal number of unpaired pm 5-HT neurons develops (Blair, 1983). This earlier failure to observe all 7 unpaired 5-HT neurons in such embryos was probably due to the use of the less sensitive assay technique of glyoxylic acid-induced fluorescence.

\section{Primary blast cells of origin of 5-HT neurons}

Alternate primary blast cells in the $\mathrm{n}$ bandlet, designated as $\mathrm{n}_{\mathrm{f}}$ and $n_{s}$, differ with respect to their initial division pattern (Zackson, 1984). The $n_{s}$ blast cell produces neurons that mainly lie in the anterior region and the $n_{f}$ blast cell produces neurons that mainly lie in the posterior region of a given ipsilateral neuromere (Bissen and Weisblat, 1987).

Injection of lineage tracer into an $\mathrm{N}$ teloblast in a late stage 6 or early stage 7 embryo; after $n$ blast cell production is under way, yields a partially labeled $\mathrm{n}$ bandlet whose anterior (older) blast cells are not labeled. The anterior ganglia formed in such an embryo contain no labeled neurons, having arisen from blast cells in the unlabeled anterior part of the bandlet. In contrast, the posterior ganglia of such an embryo contain label in all the neurons derived from the partially labeled bandlet. In such embryos the anteriormost ganglion containing any labeled neurons lics at the boundary of the label. That anteriormost labeled ganglion, containing the labeled neurons derived from the first $\mathrm{n}$ blast cell born immediately after tracer injection, may be of 1 of 2 different, equally frequent types (Weisblat et al., 1980a). In one of these types, which we will refer to as "fully labeled," 

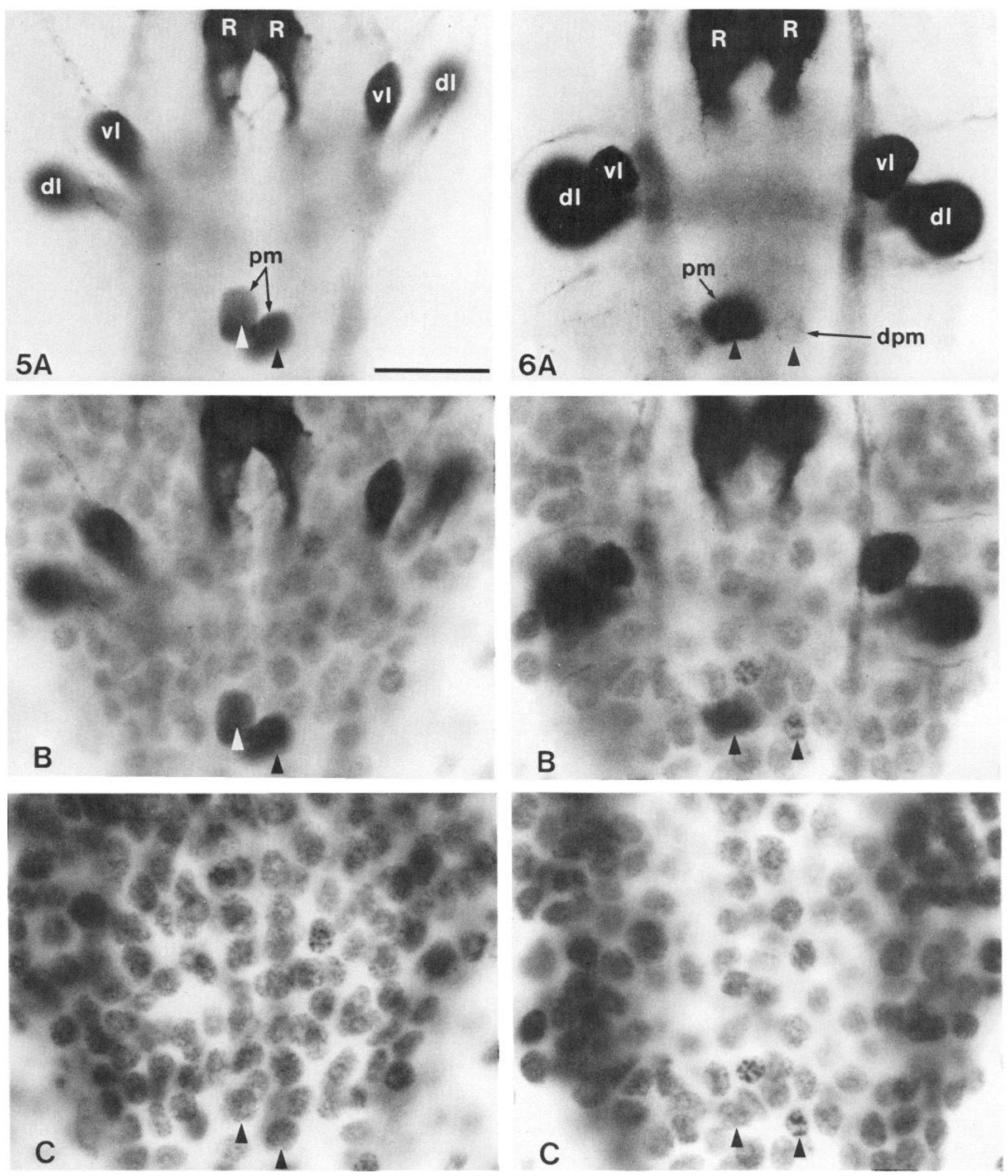

Figure 5. The pair of embryonic pm 5-HT neurons before the death of one of them. Negative fluorescence micrographs are shown of abdominal ganglion 3 from a whole-mounted, late stage $9 \mathrm{H}$. ghilianii embryo stained with the 5-HT antibody and the DNA-specific Hoechst dye. In each photograph the lower, unlabeled pair of arrowheads points to the nuclei of the pm pair of neurons. $A$, Single exposure of 5-HT immunofluorescence. Four pairs of 5-HT neurons are seen: Retzius $(R)$, ventrolateral $(v l)$, dorsolateral $(d l)$, and posteromedial $(\mathrm{pm})$. The fifth, anteromedial pair of 5 HT neurons lies mostly out of the field of view. All the 5-HT neurons have developed primary axons, generally out of focus, that account for the apparently diffuse stain throughout the ganglion. B, Double exposure of both the 5-HT immunofluorescence and Hoechst DNA-specific fluorescence. Here, the 5-HT neurons can be identified with respect to the nuclei of other ganglionic neurons. $C$, Single exposure of Hoechst dye fluorescence. The nuclei of the 2 pm neurons appear healthy (compare Fig. 6). Scale bar, $25 \mu \mathrm{m}$. 
the pattern of labeled neurons is the same as that in the more posterior ganglia. This type of boundary ganglion is derived from an $\mathrm{n}$ bandlet in which the first labeled primary blast cell was $n_{s}$. In the other type, which we will refer to as "partially labeled," only a posterior portion of the neurons is labeled. This type of boundary ganglion is derived from an $\mathbf{n}$ bandlet in which the first labeled primary blast cell was $n_{\mathrm{f}}$.

Having found that all 5-HT neurons are derived from the $n$ bandlet, we asked whether these neurons arise from one or both kinds of $\mathrm{n}$ primary blast cells. To answer this question, the posterior regions of both $\mathrm{n}$ bandlets were labeled with RDA lineage tracer in stage 7 embryos of $T$. rude. Both $\mathrm{n}$ bandlets were labeled to assure that all unpaired pm 5-HT neurons contained label regardless of whether they were derived from the left or right $\mathbf{n}$ bandlet. In each embryo labeling of both $\mathbf{n}$ bandlets was initiated (by injecting the two $\mathrm{N}$ teloblasts) within a few minutes of each other, and the labeling of a set of 30 embryos was initiated over a period of $2 \mathrm{hr}$. When they reached early stage 11,9 successfully labeled embryos were dissected, fixed, stained for 5-HT immunofluorescence, and examined in whole-mount. Because labeling of the two $n$ bandlets in each embryo had been initiated at almost the same time, for 8 of the 9 embryos the label boundary on the left and right sides fell within the same ganglion, and both hemiganglia at the boundary showed the same type of labeling pattern.

Of these 8 embryos, 4 happened to show the fully labeled type of pattern in abdominal ganglion 2 , their anteriormost labeled ganglion. The ganglia at the boundary in the other 4 embryos showed the partially labeled type of pattern, 1 in abdominal ganglion 1 and the other 3 in abdominal ganglion 2 . As expected, in both types of labeling patterns none of the 5HT neurons in the ganglia anterior to the boundary ganglion and all the 5-HT neurons in the ganglia posterior to the boundary ganglion contained the lineage tracer. Also, as expected, in the 4 ganglia of the fully labeled type-the anteromedial, Retzius, ventrolateral, and dorsolateral neuron pairs - as well as the unpaired pm neuron all contained lineage tracer. But in the 4 ganglia of the partially labeled type, only the ventrolateral and dorsolateral 5-HT neuron pairs contained tracer (Fig. 8), whereas the anteromedial, Retzius, and unpaired pm neurons did not contain tracer. ${ }^{1}$ The posteromedial region of the partially labeled ganglia contained other cells with lineage tracer but not as large a number as in the fully labeled type of ganglia.

Thus, it can be inferred that the ganglionic set of 5-HT neurons is derived from both kinds of $n$ primary blast cells: in a given hemiganglion the Retzius neuron and, if they are present at all, the anteromedial and pm 5-HT neurons are derived from the

\footnotetext{
The first primary blast cell born after a teloblast is injected with lineage tracer sometimes receives much less tracer than those born subsequently (Bissen and Weisblat, 1987). The clones of cells descended from such primary blast cells are only dimly labelee, and it is often impossible to identify all the members of the clone, but those cells recognized as being labeled are readily distinguishable from their more brightly labeled neighbors. In the 8 embryos just discussed, this occurred in 7 of the $16 \mathrm{n}$ blast cell bandlets. To avoid scoring ambiguities, these 7 dimly labeled clones were treated as unlabeled.
}

$\mathrm{n}_{\mathrm{s}}$ primary blast cell, whereas the ventrolateral and dorsolateral 5-HT neurons are derived from the $\mathrm{n}_{\mathrm{f}}$ primary blast cell.

\section{Distribution of dopamine neurons}

It is possible to visualize the dopamine neurons of leeches by virtue of their blue-green fluorescence induced by treatment with glyoxylic acid (Stuart, 1981; Lent, 1982). Evidence suggesting that this fluorescence induced in leech neurons reflects dopamine rather than just a related catecholamine is discussed in Glover ct al. (1987). Survcys of the nervous systems of $H$. triserialis, $H$. ghilianil, and $T$. rude by this method have shown that the cell bodies of most of their dopamine neurons lie outside the ventral nerve cord. The body wall of each abdominal segment of $H$. triserialis and $T$. rude contains 3 bilateral pairs of dopamine neurons (Fig. 9; Blair, 1983; Torrence and Stuart, 1986); at least 2 of these pairs are also present in $H$. ghilianii (Stuart, 1980). The largest and most medially situated of these paired neurons, designated MD (medial dopamine), is located in the ventral body wall and is associated with the medial anterior (MA) segmental nerve trunk. The MD neuron lies about halfway between the ventral midline and the lateral body edge and may be homologous to a peripheral dopamine neuron previously described in hirudinid leeches (Ehinger et al., 1968; Marsden and Kerkut, 1969; Rude, 1969; Lent, 1982; Lent et al., 1983). The other 2 pairs of dopamine neurons are located near the lateral body edge. The larger of these, designated LD1 (lateral dopamine 1), lies next to the anteroanterior (AA) segmental nerve, while the smaller, designated LD2, lies next to the posteroposterior (PP) nerve.

In the body wall of the 4 anteriormost segments, which are associated developmentally with the subesophageal ganglion, pairs of MD and LD1 neurons are absent from the anteriormost segment but are present in the other 3 segments. Pairs of LD2 neurons have sometimes been observed in the body wall of the anteriormost segment ( $T$. rude) and are present in the other 3 segments of $H$. triserialis and $T$. rude. Seven pairs of MD neurons are present in the body wall of the 7 posteriormost segments, associated developmentally with the caudal ganglion, while pairs of LD1 and LD2 neurons have not been observed in these posteriormost segments.

Each peripheral dopamine neuron projects an axon into the segmental ganglion via the adjacent segmental nerve. The details of these projections can be observed in $H$. ghilianil, which possesses at least 2 of these 3 types of peripheral dopamine neurons. Within the CNS, the MD neuron sends 1 major axon into the anterior and another major axon into the posterior connective nerve, thus projecting to both adjacent ganglia, whereas the LDl neuron sends 1 smaller, major axon only into the anterior connective nerve, thus projecting only to the antcrior ganglion (illustrated in Fig. 6 in Glover et al., 1987). The axons of the peripheral dopamine neurons arborize profusely, both in the ipsilateral neuropil of the ganglion of entry and in that of the adjacent ganglia to which they project.

The cell bodies of a few other types of dopamine neurons are

Figure 6. Death of 1 member of the pm 5-HT neuron pair. Abdominal ganglion 3 from a whole-mounted, early stage $10 H$. ghilianii embryo prepared and photographed as the preparation shown in Figure 5. In each photograph the lower, unlabeled pair of arrowheads points to the nuclei of the surviving (left) and dying (right) members of the pm neuron pair. $A, 5-\mathrm{HT}$ immunofluorescence. The dying pm neuron (dpm) shows only faint fluorescence. The other 5-HT neurons (see Fig. 5) show bright fluorescence. $B$, Double exposure of both the 5-HT immunofluorescence and Hoechst DNA-specific fluorescence. $C$, Hoechst fluorescence. The healthy and pyknotic nuclei of the 2 pm neurons can be seen. A second pyknotic nucleus is present nearby. Same scale as in Figure 5. 


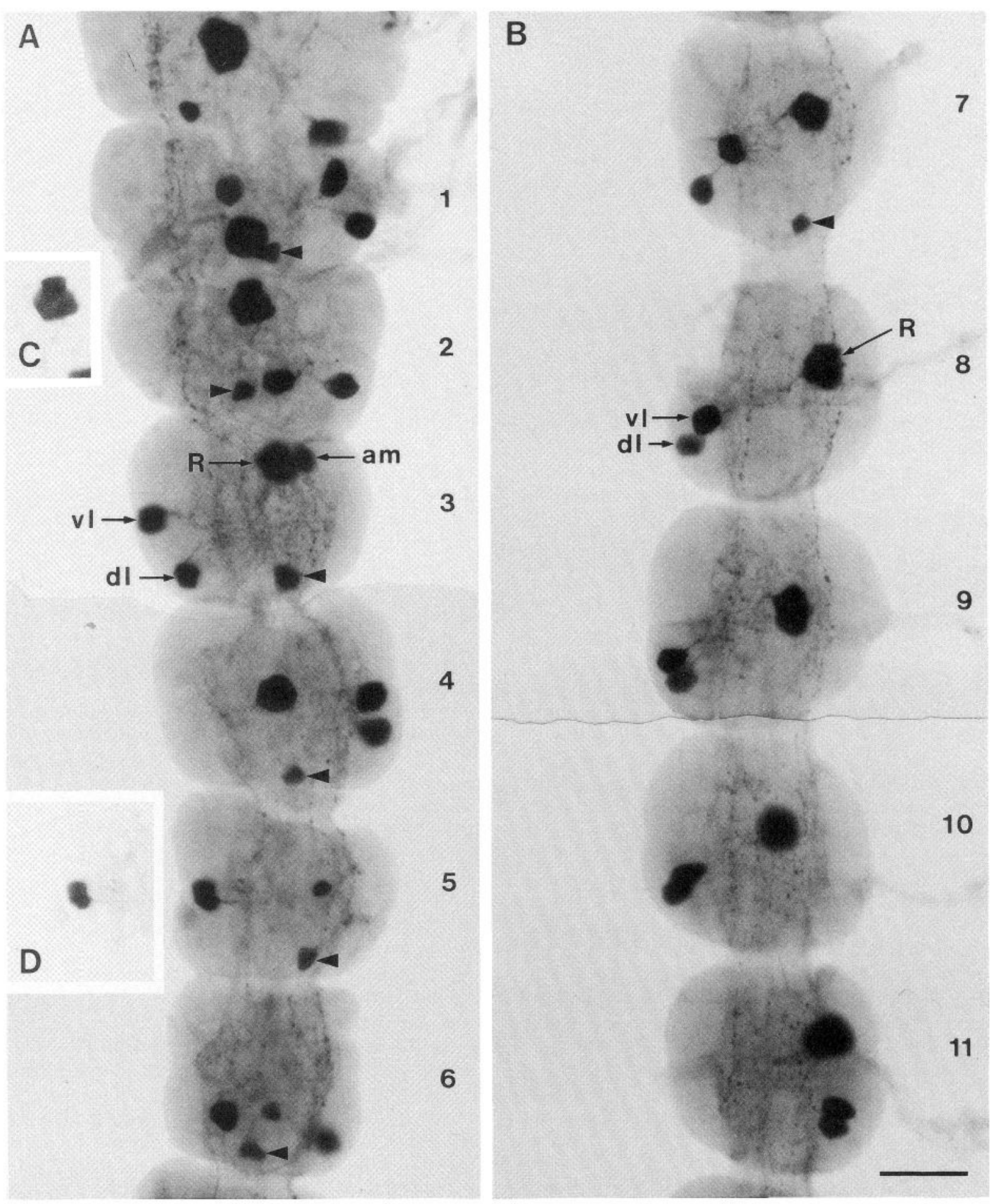

Figure 7. 5-HT neurons remaining in the whole-mounted nerve cord of an $H$. triserialis embryo after formation of one of its two $\mathrm{n}$ bandlets was aborted by ablation in stage 6 of its parent $\mathrm{N}$ teloblast. The negative fluorescence images $(A, B)$ show the immunofluorescent 5-HT neurons in the anteriormost 11 abdominal ganglia of a midstage 11 embryo. One member of each pair of 5-HT neurons survives in each of the first 7 abdominal ganglia, including a pm neuron (arrowheads). Half of these unpaired pm neurons would normally have been derived from the absent $\mathrm{n}$ bandlet (see Table 2). Each of the first 3 ganglia also contains a single anteromedial $(\mathrm{am})$, Retzius $(R)$, ventrolateral $(\mathrm{v} l)$, and dorsolateral $(\mathrm{dl})$ neuron. As in normal embryos, ganglia 4-11 lack the anteromedial neuron, Retzius is smaller in the genital ganglia, 5 and 6 , than in other ganglia, and ganglia 8-11 lack the pm neuron. Insets $C$ and $D$ are each printed to reveal the presence of 2 overlapping neurons. The nerve cord is twisted by $180^{\circ}$ between ganglia 2 and 3 so that the apparent left side is actually the right side in ganglia 1 and 2 . It is not known whether the left or right $\mathrm{n}$ bandlet was absent, but the surviving 5-HT neurons have distributed themselves on both sides of the ganglia in what are otherwise relatively normal positions (see Blair, 1983). Criteria for identifying each type of 5-HT neuron were the size, shape, and position of the cell body and the direction of its main axonal projection (D. Stuart and J. Glover, unpublished observations). Scale bar, $25 \mu \mathrm{m}$. 

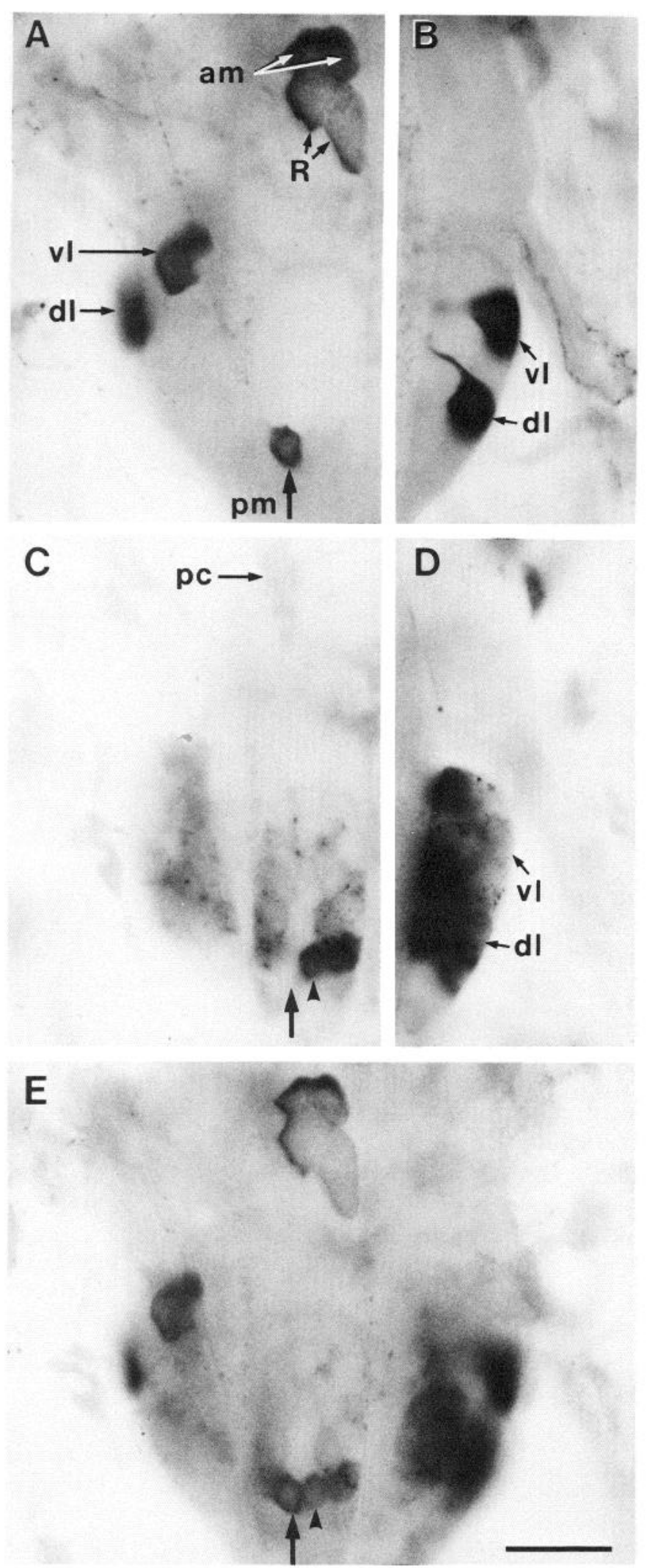

Figure 8. Primary blast cells of origin of the 5-HT neurons as revealed in the anteriormost abdominal ganglion containing lineage tracer. Negative fluorescence images of abdominal ganglion 1 in a whole-mounted, stage 11 embryo of $T$. rude. Both n bandlets were simultaneously labeled by injection of RDA lineage tracer into their parental $\mathrm{N}$ teloblasts in early stage 7 after some unlabeled primary blast cells had already been formed. The embryo was fixed during stage 11 and stained with 5-HT

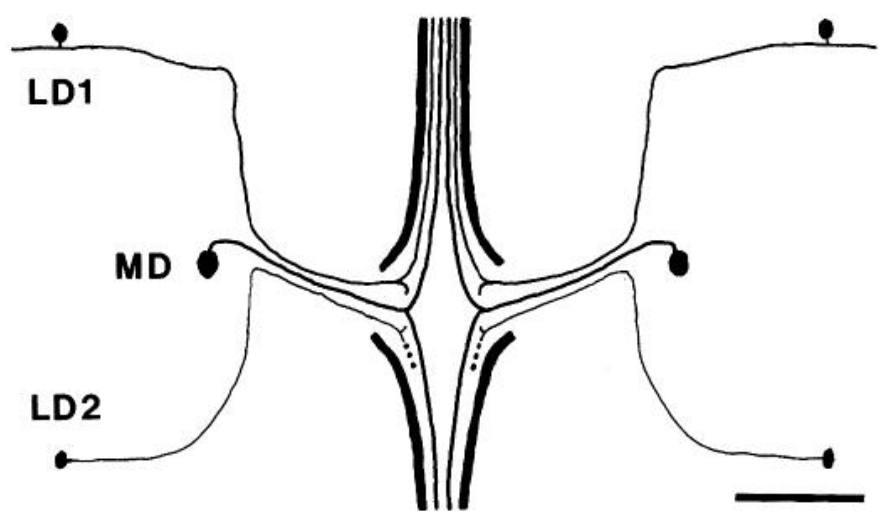

Figure 9. Diagram of the distribution and major axonal projections of 3 pairs of dopamine neurons (LD1, LD2, and MD) in the ventral body wall of 1 segment of an adult $H$. triserialis. The segmental ganglion with its connective nerves is outlined by heavy lines. The projection pattern of LD2 within the ganglion is not known. Although the axons of the dopamine neurons appear to enter the ganglion via a common segmental root, in the stage 11 embryo they project into the ganglion via 3 distinct nerves. This illustration is based on the segment containing abdominal ganglion 4; in most posterior segments, mediolateral distances are greater. Scale bar, $100 \mu \mathrm{m}$.

found in the leech ventral nerve cord. Four pairs of dopamine neurons are present in the nonsegmental supraesophageal ganglion of $H$. ghilianii, of which at least 2 are also present in $H$. triserialis and $T$. rude. In all 3 species the anteriormost neuromere of the subesophageal ganglion contains a triplet of dopamine neurons on each side. And finally, another lightly staining pair is often, but not invariably, observed in some of the neuromeres of the subesophageal and caudal ganglia, as well as the nearby abdominal ganglia.

\section{Primary blast cells of origin of dopamine neurons}

To ascertain the developmental origin of the dopamine neurons, specific blast cell bandlets were labeled with RDP lineage tracer by a single injection into a precursor blastomere. In a series of $H$. triserialis embryos the teloblast or blastomere was injected with cell lineage tracer within an hour of its birth, in order to insure the presence of label in all of the primary blast cells that it produced. The embryos were then raised to midstage 11, by which time all dopamine neurons are clearly identifiable. Each dopamine neuron on the injected side of each embryo, identified

immunocytochemistry. $A$ and $B, 5$-HT immunofluorescence. $A$ shows the left and middle part of the ganglion at a ventral plane of focus, $B$ the right part of the ganglion at a more dorsal plane of focus. All 5 types of 5-HT neurons are present (see Fig. $2 A$ ). $C$ and $D$, RDA lineage tracer fluorescence at the same planes of focus as $A$ and $B$, respectively. On both left and right sides of the nerve cord the boundary between unlabeled and labeled $n$ blast cell clones falls within the middle of this ganglion. Hence, this "partially labeled" ganglion contains on both sides an unlabeled $\mathrm{n}_{\mathrm{s}}$ and a labeled $\mathrm{n}_{\mathrm{f}}$ clone. $E$, Double-exposure photomicrograph showing both RDA fluorescence and 5-HT immunofluorescence of the entire ganglion at the ventral plane of focus. The anteromedial $(\mathrm{am})$ and Retzius $(R)$ neurons lack lineage tracer and are thus derived from an $n_{s}$ primary blast cell. Although situated among tracerlabeled cells, the pm 5-HT neuron (pm and arrows) is unlabeled, and thus also derived from an $\mathrm{n}_{\mathrm{s}}$ primary blast cell. The ventrolateral $(v l)$ and dorsolateral $(d l)$ 5-HT neurons do contain tracer label, and are thus derived from an $\mathrm{n}_{\mathrm{f}}$ primary blast cell. $p c$, Faint autofluorescent pigment cell situated outside the ganglion; arrowheads, a tracer-labeled neuron adjacent to the pm 5-HT neuron. Scale bar, $25 \mu \mathrm{m}$. 
by glyoxylic acid-induced fluorescence, was scored for the presence or absence of the RDP lineage tracer.

The results of this experiment, summarized in Table 4, indicate that in most, if not all, cases the dopamine neurons LD2, $\mathrm{I} D 1$, and $\mathrm{MD}$ are not derived from the $\mathrm{n}$ bandlet but rather from the $o, p$, and $q$ bandlets, respectively. (The inhomogeneous, granular distribution of RDP tracer within neurons of stage 11 $H$. triserialis embryos does not always permit a clear distinction in whole-mounted preparations between neurons that contain RDP and those that do not. Errors arising from this difficulty probably account for our few atypical results.) Of the 2 daughter cells generated by cleavage of the OPQ blastomere, it is the $\mathrm{Q}$ teloblast producing the $\mathrm{q}$ bandlet that gives rise to dopamine neuron MD, and it is the OP blastomere, from which the o and $\mathrm{p}$ bandlets are derived, that gives rise to dopamine neurons LD2 and LD1. This confirms the earlier tentative conclusion based on ablation experiments that 1 set of dopamine neurons is derived from the $\mathrm{Q}$ teloblast and another set from the OP blastomere (Blair, 1983). The labeled MD dopamine neurons included those in the body wall associated with the caudal ganglion, indicating that these posteriormost MD neurons are also derived from the $\mathrm{q}$ bandlet. Finally, of the 2 bandlets produced by the sister $\mathrm{O} / \mathrm{P}$ teloblasts, the o bandlet gives rise to dopamine neuron LD2 and the $p$ bandlet to dopamine neuron LD1 (Fig. 10).

No further experiments are necessary to identify the primary blast cell from which each of these dopamine neurons is derived. Since only $1 \mathrm{o}$ and only $1 \mathrm{p}$ primary blast cell generate 1 hemisegmental complement of progeny, dopamine neuron LD1 necessarily belongs to the $\mathrm{p}$ blast cell clone and dopamine neuron LD2 to the o blast cell clone. As for the 2 different q blast cells that produce the progeny of 1 hemisegmental complement, it has been shown that cells of the ventral body wall, where the dopamine neuron $\mathrm{MD}$ is located, are derived from only 1 of the 2 q blast cells (Zackson, 1984; Weisblat and Shankland, 1985; S. Torrence, personal communication).

In the experiments reported in Table 4, observations were also made on some central dopamine neurons of the ventral nerve cord. The injection of the OPQ blastomeres did not result in the presence of any label in the supraesophageal ganglion in which at least 2 pairs of dopamine neurons are located. The supraesophageal ganglion, and hence these dopamine neurons, are probably derived from micromeres produced by the $\mathrm{A}, \mathrm{B}$, C, and D macromeres (Weisblat et al., 1984). The triplet of dopamine neurons found on each side of the anteriormost neuromere of the subesophageal ganglion was identified in 2 of the 5 embryos with OPQ injected blastomeres. This triplet of neu- rons contained lineage tracer on the injected side, suggesting that these dopamine neurons are derived from the OPQ blastomere. Finally, no observations were made on the faintly staining pair of dopamine neurons found in the subesophageal and caudal ganglia.

The OP blastomere produces several primary blast cells (designated op) before cleaving to form the 2 sister $\mathrm{O} / \mathrm{P}$ teloblasts. About 4 op primary blast cells are produced in $H$. triserialis (Weisblat et al., 1984; M. Shankland, personal communication). The clones of cells derived from the op blast cells populate the anteriormost segments of the embryo. For $H$. triserialis these are the first 4 or so segments associated with the neuromeres of the subesophageal ganglion. The close correspondence between the number of op primary blast cells produced and the number of segments containing progeny of the op blast cells suggests that each segment received one complement's worth of op progeny.

Does the prospective fate of each op blast cell correspond to the prospective fate of either an o or p primary blast cell, or is the prospective op fate the sum of the $o$ and $p$ fates? The experiments reported in Table 4 suggest an answer to this question. Since the OP blastomere or the $\mathrm{O} / \mathrm{P}$ sister teloblasts were injected with tracer during the first hour after their birth, all the primary blast cells produced by them should contain label. First, we observed that the anteriormost 3 or so LD1 and LD2 neurons are always unlabeled, falling in unlabeled segments, following injection of the $\mathrm{O} / \mathrm{P}$ sister teloblasts, indicating that in these segments the 2 dopamine neurons are not derived from o or $\mathrm{p}$ primary blast cells. Second, any LD1 and LD2 neuron can be labeled on the side of an injected OP blastomere, indicating that the anteriormost 3 or so LD1 and LD2 neurons are derived from op primary blast cells. These LD1 and LD2 neurons are found in the segments associated with about the last 3 neuromeres of the subesophageal ganglion. So, it would appear that 3 (or possibly 4) op blast cells each normally produces an LD1 and an LD2 neuron. We conclude that with respect to giving rise to $\mathrm{LD} 1$ and $\mathrm{LD} 2$ neurons an op primary blast cell can combine the prospective fate of both an o primary and a $p$ primary blast cell.

\section{Discussion}

\section{Blast cells of origin}

The results presented here demonstrate that all 5-HT neurons of the leech ventral nerve cord are derived from the pair of $n$ blast cell bandlets. Each $\mathbf{n}$ bandlet contains 2 alternating types of primary blast cells, $n_{s}$ and $n_{f}$ (Zackson, 1984), of which one

Table 4. Lineage tracer labeling of identified dopamine neurons

\begin{tabular}{llccccc} 
Dopamine & \multicolumn{6}{l}{ Labeled bandlets (no. of specimens) } \\
\cline { 2 - 7 } neuron & $\mathrm{n}(5)$ & $\mathrm{o}(5)$ & $\mathrm{p}(7)$ & $\mathrm{q}(5)$ & $\mathrm{o}$ and p (5) & o, p, and q (5) \\
\hline MD & $2 / 81(2 \%)$ & $2 / 84(2 \%)$ & $7 / 96(7 \%)$ & $\underline{47 / 49(96 \%)}$ & $15 / 96(16 \%)$ & $\underline{34 / 37(92 \%)}$ \\
LD1 & $1 / 82(1 \%)$ & $0 / 75(0 \%)$ & $\frac{76 / 97(78 \%)}{13 / 83(16 \%)}$ & $\underline{77 / 90(86 \%)}$ & $\underline{\underline{31 / 40(78 \%)}}$ \\
LD2 & $2 / 68(3 \%)$ & $\underline{68 / 69(99 \%)}$ & $2 / 91(2 \%)$ & $6 / 75(8 \%)$ & $\underline{59 / 61(97 \%)}$ & $\underline{31 / 32(97 \%)}$
\end{tabular}

For each of 3 identified dopamine neurons, the ratios here consist of the number of scored cells containing lineage tracer divided by the number of cells of that type scored. Bandlets were labeled by a single injection of tracer into a precursor blastomere $(\mathrm{N}, \mathrm{O} / \mathrm{P}, \mathrm{Q}, \mathrm{OP}$, or $\mathrm{OPQ})$ in stage 6 embryos, the embryos were raised to early stage 11 , and dopamine fluorescence was induced by glyoxylic acid. The dopamine neurons were scored in whole-mounted preparations. (Neurons were scored only on the same side of the embryo as the labeled bandlets and only in the labeled segments on that side.) The underlined data indicate labeled bandlets that produced lineage tracer in a given neuron in the great majority of cases. 

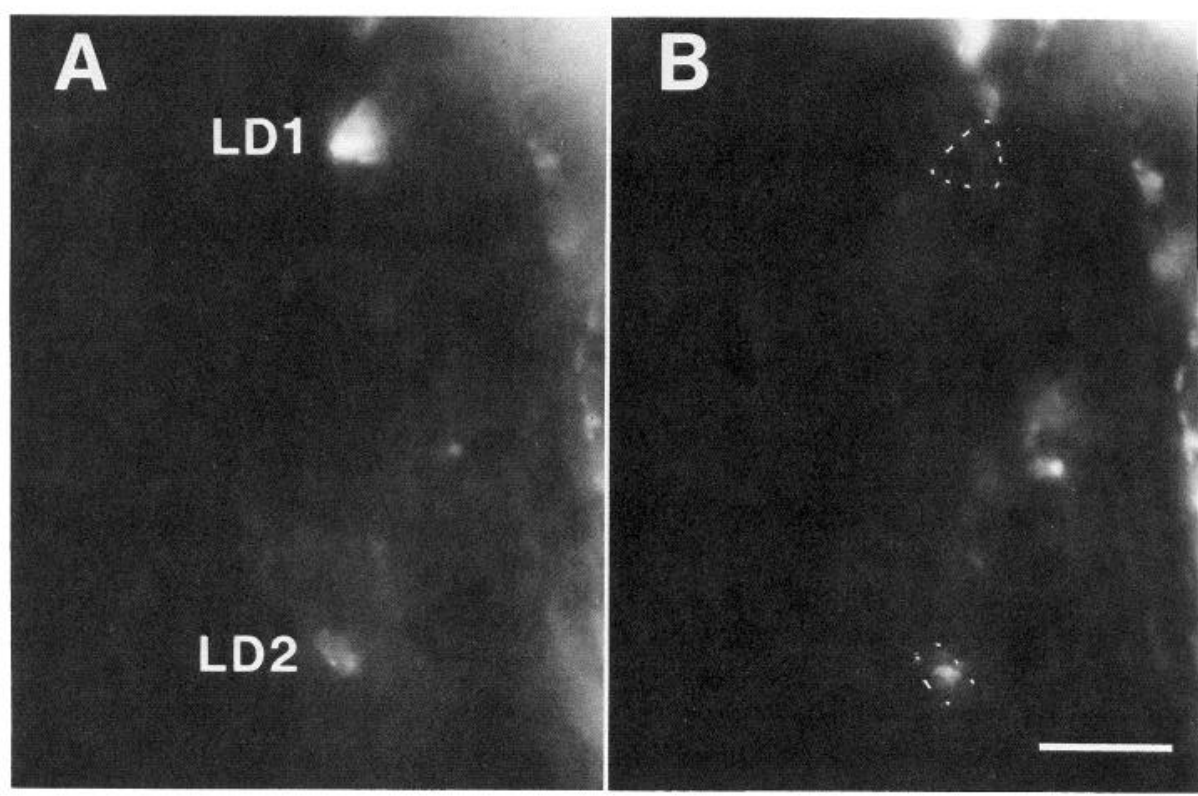

Figure 10. Blast cell bandlets of origin of dopamine neurons. Fluorescence photomicrographs of the segmental body wall from a whole-mounted embryo of $H$. triserialis. The o bandlet was labeled by injection of RDA lineage tracer into one of the sister O/P teloblasts at stage 6 . The embryo was dissected at stage 11 and dopamine fluorscence induced by the glyoxylic acid reaction. $A$, Glyoxylic acid-induced fluorescence in the dopamine neurons LD1 and LD2. B, RDA lineage tracer fluorescence. The positions of the cell bodies of neurons LD1 and LD2 are shown with dashed outlines. Lineage tracer fluorescence is seen in neuron LD2, but not in LD1; thus dopamine neuron LD2, but not LD1, is derived from the o bandlet. Analogous experiments (not shown) in which the p bandlet or q bandlet was labeled with lineage tracer show dopamine neuron LD1 to be derived from the $\mathrm{p}$ bandlet and dopamine neuron MD to be derived from the q bandlet. Embryos with labeled o or $\mathrm{p}$ bandlets were distinguished at stage 11 by their distinctive pattern of tracer in the nerve cord. Scale bar, $10 \mu \mathrm{m}$.

$\left(n_{s}\right)$ contributes most of its neurons to the anterior part of a hemiganglion and the other $\left(n_{f}\right)$ contributes most of its neurons to the posterior part of a hemiganglion (Bissen and Weisblat, 1985). The $n_{s}$ blast cell gives rise to the Retzius neuron, to the anteromedial 5-HT neuron (in abdominal ganglia 1-3) and to the unpaired pm 5-HT neuron (in an apparent random half of the abdominal ganglia $1-7$ ), while the $n_{f}$ blast cell gives rise to the ventrolateral and dorsolateral 5-HT neurons. Thus, although the 5-HT neurons of any hemiganglion are all progeny of an n bandlet, they belong to 2 different primary blast cell clones.

The dopamine neurons lying in the body wall are all derived from the $o, p$, and $q$ bandlets. Here, too, a single hemisegmental complement does not arise from a single primary blast cell: the MD neuron arises from that one of two types of alternating $\mathrm{q}$ blast cells that contributes its descendants to the ventral body wall, the LD1 neuron arises from the single type of $\mathrm{p}$ blast cell, and the LD2 neuron from the single type of o blast cell. Moreover, the dopamine neurons of the supraesophageal ganglion are probably derived from the micromeres generated by the 4 macromeres.

\section{Determinacy of the lineage pattern}

The examination of sections of tracer labeled embryos summarized in Table 1 reveals a very high degree of determinacy in the cell lineage relationships between differentiated 5-HT neurons and their bandlets of origin. Thus, in the embryos in which an $n$ bandlet had been labeled, all 98 of the 5-HT neurons examined on the labeled side and none of the 98 examined on the other side contained tracer. By contrast, in the embryos in which the $o, p$, and $q$ bandlets had been labeled, none of the 107 5-HT neurons examined on the labeled side contained tracer. This high degree of determinacy with which a given pair of leech bandlets gives rise to a set of identified neurons is consistent with previous findings that the leech embryo develops via a stereotyped sequence of cell divisions, and that the various structures of the mature leech body arise from specific embryonic cell lines.

The technique employed to identify the developmental origin of the dopamine neurons in whole-mounted $H$. triserialis embryos produced results with some variability (Table 4 ); this variability is probably artifactual and not a consequence of indeterminate cell lineage patterns. First, in $H$. triserialis wholemounted embryos lineage tracer analysis of the 5-HT neurons, other than the unpaired pm neuron, produced a similar variability (data not reported); this variability disappeared when the more precise analysis of serial sections was employed (Table 1). Second, in experiments in which single blastomeres (N, OP, or Q) were ablated, resulting in the loss of the respective $n$, o and $\mathrm{p}$, or $\mathrm{q}$ bandlet, no variability was observed in the types of dopamine neurons lost (Blair, 1983), and the pattern of loss corresponded precisely to the developmental origins reported here. Hence, the dopamine neurons are probably also formed via a highly determinate lineage. This conclusion is supported by observations in $T$. rude embryos, where $\mathrm{q}$ bandlets or $\mathrm{p}$ bandlets labeled with lineage tracer produced no variability in the labeling of MD or LD1 dopamine neurons, respectively (D. Stuart and S. Torrence, unpublished observations). This lack of variability is probably due to the larger size of $T$. rude embryonic nerve cords and the use of a more brightly fluorescent cell lineage tracer, RDA, instead of RDP.

\section{Unpaired pm neuron}

In adult abdominal ganglia 1-7 the pm 5-HT neuron is present as an unpaired neuron. At the beginning of stage 10, when the 
pm neuron has just begun to contain an appreciable concentration of 5-HT and has extended its first neurite, abdominal ganglia 1-7 actually contain a pair of pm neurons. Soon thereafter, however, either the left or the right pm neuron dies, with the selection of the moribund member of the pair apparently varying randomly from ganglion to ganglion. Similar observations have been made for the homologous unpaired 5-HT neuron in the hirudinid leeches Hirudo medicinalis, Haemopis marmorata (Macagno et al., 1985), and Macrobdella decora (D. Stuart and J. Glover, unpublished observations).

Embryonic cell death is common in the development of both vertebratc (Hamburger and Oppenheim, 1982) and invertebrate (Truman, 1984) nervous systems. In the leech embryo the pyknotic nuclei of the dying pm neurons develop clumps of condensing chromatin near their surface and later, after 5-HT can no longer be detected in the neurons, collapse into a small mass. These light-level observations are consistent with the findings of ultrastructural studies on larval cell death in the nematode Caenorhabditis elegans (Robertson and Thomson, 1982). In the nematode embryo many cells die just after being born, but others, similar to the leech pm neuron, start to differentiate before dying (Sulston et al., 1983).

The decision as to which member of a nascent pm neuron pair is to die and which is to survive is the result of a direct or indirect interaction between cells derived from the left and the right $\mathrm{n}$ bandlets. This follows from our finding that the absence of one $n$ bandlet, following ablation of its precursor teloblast, assures the survival of every pm 5-HT neuron derived from the other $\mathrm{n}$ bandlet. In $H$. triserialis embryos the outcome of this interaction in one ganglion appears to have little or no effect on the outcome in adjacent ganglia, although in adjacent ganglia of some clutches of $H$. ghilianii embryos the surviving pm neuron often alternates between left and right sides. These results do not identify the cells that are the primary participants in this interaction, nor do they indicate the time at which the interaction and the commitment to death or survival actually occurs. One plausible hypothesis would be that the nascent pm neurons interact directly with one another to determine which of them will die. Alternatively, as both members of the pm pair differentiate they might compete with each other for a limited resource necessary for continued survival, such as an axonal growth pathway, postsynaptic target, or a presynaptic input. Such competition is common in the development of vertebrate nervous systems (Hamburger and Oppenheim, 1982).

This latter hypothesis could also explain why there are no pm 5 -HT neurons in abdominal ganglia $8-21$. If in those ganglia the putative resource required for survival of pm neurons is not present at all, both members of the embryonic neuron pair might die before they have accumulated enough 5-HT to become identifiable by 5 -HT immunfluorescence. From this perspective, a basic set of lecch neurons may be formed initially in all segements, with cell death generating subequent segmental differences. Our data are consistent with several alternative explanations: either that in abdominal ganglia 8-21 one or both members of the pm neuron pair do survive but do not synthesize a detectable level of 5-HT and hence are not classified as 5-HT neurons or that the pattern of cell lineage in these segments is different, so that the pm neuron pair is not generated at all.

These findings indicate that, in contrast to the general tendency for cell lineage relationships to be invariant, the precursors of the pm 5-HT neurons can take on either 1 of 2 different prospective fates. Which of these fates, survival or death, is actually taken does not depend on the lineal origin of the cell, but rather on the outcome of intercellular interactions in the course of embryogenesis. An intercellular interaction also determines the lineage relationships reported here for the LD1 and LD2 neurons and has been previously reported (Shankland and Weisblat, 1984; Weisblat and Blair, 1984). Except for the most anterior neurons, the LD1 neurons are derived from the $p$ bandlet and the LD2 neurons from the o bandlet, but which sister $\mathrm{O} / \mathrm{P}$ teloblast produces either the $\mathrm{p}$ or o bandlet depends upon an interaction between cells of the germ band, so that the $\mathrm{O} / \mathrm{P}$ generated bandlet that comes to lie next to the $\mathrm{q}$ bandlet assumes the fate of the $p$ bandlet and the other $\mathrm{O} / \mathrm{P}$-generated bandlet assumes the fate of the o bandlet.

The 2 members of the embryonic pair of pm 5-HT neurons thus represent another instance of the developmentally equivalent, pluripotent cell sets, designated as "equivalence groups," that have been brought to light by cell lineage studies in nematodes, leeches, and insects (Kimble, 1981; Weisblat and Blair, 1984; Doe and Goodman, 1985; Kuwada and Goodman, 1985). In the present case the primary fate (Sulston and White, 1980) of the equivalence group is survival; 1 member of the equivalence group always takes on this fate. The secondary fate of this equivalence group is death, which is taken on by 1 member of the group when both members are present. We do not know the time at which the pluripotential pm neuron is actually committed to take on its primary or its secondary fate, but such commitment must occur independently of the commitment to synthesize the 5-HT neurotransmitter and grow a primary axon, which both members of the pair initiate.

In general, the cells of an equivalence group are of similar lines of descent, and if any cell of the group is ablated early enough, then another cell of the group always expresses the primary fate. In some cases, a cell becomes committed to the secondary fate after first assuming a definable position relative to the other cell(s) of the equivalence group (Sulston and White, 1980; Kimble, 1981; Shankland and Weisblat, 1984; Weisblat and Blair, 1984), but in other cases commitment to the secondary fate appears to occur before gross, predictable differences in position are evident (Kuwada and Goodman, 1985). The latter appears to be the case for the pair of pm 5-HT neurons, since no correlation was observed between which member of the pair dies and their relative anteroposterior or mediolateral positions within the ganglion.

The adult leech nervous system contains other unpaired neurons, in addition to the pm 5-HT neuron, such as interneurons whose axons project intersegmentally via the connective nerves linking adjacent ganglia of the ventral nerve cord (Muller et al., 1981). The developmental origin of one such identified, unpaired interneuron, $\mathrm{pz} 4$, has been identified as the $\mathrm{p}$ bandlet (Kramer and Weisblat, 1985; Weisblat and Shankland, 1985). The genesis of the unpaired $\mathrm{pz} 4$ neuron resembles that of the unpaired pm 5-HT neuron, in that the pz4 neuron arises from the left $p$ bandlet in half of the ganglia, and from the right $p$ bandlet in the other half. Here, too, the unpaired neuron represents the lone survivor of an initial pair of identifiable pz4 neurons of which one apparently randomly selected member eventually dies in late stage 9 (D. Stuart, M. Shankland, and S. Torrence, unpublished observations). Thus, the present findings regarding genesis of the unpaired pm 5-HT neuron could be generally applicable to the genesis of unpaired neurons in the leech. All such unpaired neurons might initially arise as members of a bilateral pair, of which one or the other member later 
dies as a result of some form of competitive interaction. This proposal is consistent with observations that as many as $15 \%$ of all cells present in early embryonic leech ganglia eventually disappear (Macagno et al., 1983; Stewart and Macagno, 1984).

\section{Cell lineage patterns}

The present findings lend further support to the general conclusion, drawn from developmental cell lineage analyses in nematodes (Sulston et al., 1983), as well as leeches (Shankland and Weisblat, 1984; Weisblat et al., 1984; Stent, 1985), that cells of similar phenotype often occupy positions in the cell lineage tree that are far apart. The cell lineage tree giving rise to a hemisegmental complement of neurons could be organized in several different ways to give rise to a number of 5-HT or dopamine neurons. First, all the neurons of a given type could be produced on the same outer branch of the lineage tree, as is thought to be the case for the 5-HT neurons in the grasshopper embryo (Taghert and Goodman, 1984). Our results indicate that this is not the case for the 5-HT and dopamine neurons in the leech embryo. The five 5-HT neurons are separated into 2 groups upon formation of the $n_{f}$ and $n_{s}$ primary blast cells and the three dopamine neurons are separated upon formation of the $o, p$, and q primary blast cells with each of these primary blast cells giving rise to several other neuronal and non-neuronal types. However, the separation between the 2 neurotransmitter types also occurs early in the lineage tree; our data suggest that in the cleavage of the NOPQ blastomere into the N and OPQ blastomeres the capacities for producton of 5-HT and dopamine neurons may be separated. It remains to be determined whether this separation actually reflects a concurrent process of commitment to one or the other neurotransmitter type.

A second possibility is that neurons of the same type arise on different branches of the lineage tree and that the pattern of divisions leading to a particular type is homologous for all lineages. Similar cases have been observed in the development of nematodes (Sulston et al., 1983). In the leech such parallel pathways account for the formation of reiterated segments, so that every primary blast cell of a given type follows a parallel cell lineage pathway to generate a homologous hemisegmental complement of cells (Zackson, 1982, 1984; Weisblat et al., 1984; Stent, 1985; Weisblat and Shankland, 1985). Such pathways could also occur within a hemisegmental complement: the 3 dopamine neurons could be derived from their different precursor blast cells by parallel cell lineages, and the 2 types of 5-HT neurons derived from $n_{s}$ may have a lineage pathway similar to the 3 types derived from $\mathrm{n}_{\mathrm{f}}$.

Finally, each of the patterns of cell lineage by which the various monoamine neurons of a hemisegment are derived from their primary blast cells could differ from one another. Our current knowledge about the lineage pattern of the cells derived from each type of primary blast cell (Zackson, 1984; Braun, 1985; Shankland, 1987) is insufficient to distinguish among these 3 alternatives, beyond our conclusion that cells of a given type, such as 5-HT or dopamine neurons, need not be closely related in their lineage.

\section{Cell migration}

Many of our results are consistent with differentiated cells arising in positions close to where they are actually needed, as a consequence of the spatially ordered sequence of cell divisions in the lineages that produce them (Stent, 1985). For example, in individual hemisegments the 5-HT neurons in the anterior half of the ganglion (Retzius and anteromedial neurons) are derived from the $n_{s}$ blast cell from which most other neurons in the anterior portion of the hemiganglion are derived, while posteriorly positioned 5-HT neurons (ventrolateral and dorsolateral neurons) are derived from the $\mathbf{n}_{\mathrm{f}}$ blast cell, from which most other neurons in the posterior portion of the hemiganglion are derived.

Other results of ours suggest, however, an important role for cell migration in the development of the stereotyped positions of leech monoamine neurons. For example, the pm neuron in the posterior part of the ganglion is derived from the $n_{s}$ blast cell, most of whose other progeny lie in the anterior part of the ganglion. This suggests that in the course of gangliogenesis the $\mathrm{pm}$ neuron, or its precursor cell, migrates posteriorly from the site at which it originates to its definitive position. Also, it has been shown that the MD dopamine neuron, or its precursor, derived from one of the two $\mathrm{q}$ blast cells, migrates from a site of origin initially lateral to the $o$ and $p$ blast cells to a definitive position medial to the $\mathbf{p}$ - and o-blast cell-derived LD1 and LD2 dopamine neurons (Weisblat et al., 1984; Torrence and Stuart, 1986). Other evidence indicates that the ID1 and I.D2 neurons migrate laterally before their final differentiation (Braun, 1985). Such migration of embryonic cells is common in nervous system morphogenesis (Rakic, 1971; Sulston et al., 1983; Le Douarin, 1984; Kuwada and Goodman, 1985), and in the leech we expect that more cases of cell migration will be discovered as our level of analysis becomes finer.

\section{References}

Bissen, S. T., and D. A. Weisblat (1987) Early differences between alternate $\mathrm{n}$ blast cells in leech embryo. J. Neurobiol. (in press).

Blair, S. S. (1982) Interactions between mesoderm and ectoderm in segment formation in the embryo of a glossiphoniid leech. Dev. Biol. 89: 389-396.

Blair, S. S. (1983) Blastomcrc ablation and the developmental origin of identified monoamine-containing neurons in the leech. Dev. Biol. 95: 65-72.

Blair, S. S., and D. K. Stuart (1982) Monoamine-containing neurons of the leech and their teloblast of origin. Soc. Neurosci. Abstr. 8: 16.

Blair, S. S., and D. A. Weisblat (1982) Ectodermal interactions during neurogenesis in the glossiphoniid leech Helobdella triserialis. Dev. Biol. 91: 64-72.

Braun, J. (1985) Cells that guide the growth of neuronal processes in the leech embryo. Ph.D. dissertation, University of California, Berkeley, CA.

de la Torre, J. C., and J. W. Surgeun (1976) A methodological approach to rapid and sensitive monoamine histofluorescence using a modified glyoxylic acid technique: The SPG method. Histochemistry 49: 8193.

Doe, C. Q., and C. S. Goodman (1985) Early events in insect neurogenesis. I. Development and segmental differences in the pattern of neuronal precursor cells. Dev. Biol. 111: 193-205.

Ehinger, B., B. Falck, and H. E. Myhrberg (1968) Biogenic monoamines in Hirudo medicinalis. Histochemie 15: 140-149.

Fernandez, J. (1980) Embryonic development of the glossiphoniid leech Theromyzon rude: Characterization of developmental stages. Dev. Biol. 76: 245-262.

Giloh, H., and J. W. Sedat (1982) Fluorescence microscopy: Reduced photobleaching of rhodamine and fluorescein protein conjugates by $n$-propyl gallate. Science 217: 1252-1255.

Gimlich, R. L., and J. Braun (1985) Improved fluorescent compounds for tracing cell lineage. Dev. Biol. 109: 509-514.

Glover, J. C. (1987) Serotonin storage and uptake by identificd ncurons in the leech Haementeria ghilianii. J. Comp. Neurol. (in press).

Glover, J. C., D. K. Stuart, H. T. Cline, R. E. McCaman, C. Magill, and G. S. Stent (1987) Development of neurotransmitter metabolism in embryos of the leech Haementeria ghilianii. J. Neurosci. 7: $581-594$. 
Hamburger, V., and R. W. Oppenheim (1982) Naturally occurring neuronal death in vertebrates. Neurosci. Comment. 1: 39-55.

Henderson, L. P. (1983) The role of 5-hydroxytryptamine as a transmitter between identified leech neurones in culture. J. Physiol. (Lond.) 339: 311-326.

Henderson, L. P., D. P. Kuffler, J. G. Nicholls, and R.-I. Zhang (1983) Structural and functional analysis of synaptic transmission between identified leech neurones in culture. J. Physiol. (Lond.) 340: 347-358.

Kimble, J. (1981) Alterations in cell lineage following laser ablation of cells in the somatic gonad of Caenorhabditis elegans. Dev. Biol. 87: 286-300.

Kramer, A. P., and J. R. Goldman (1981) The nervous system of the glossiphoniid leech Haementeria ghilianii. I. Identification of neurons. J. Comp. Physiol. 144: 435-448.

Kramer, A. P., and J. Y. Kuwada (1983) Formation of the receptive fields of leech mechanosensory neurons during embryonic development. J. Neurosci. 3: 2474-2486.

Kramer, A. P., and D. A. Weisblat (1985) Developmental neural kinship groups in the leech. J. Neurosci. 5: 388-407.

Kuwada, J. Y., and C. S. Goodman (1985) Neuronal determination during embryonic development of the grasshopper nervous system. Dev. Biol. 110: 114-126.

Kuwada, J. Y., and A. P. Kramer (1983) Embryonic development of the leech nervous system: Primary axon outgrowth of identified neurons. J. Neurosci. 3: 2098-2111.

Lcakc, L. D., S. G. Griffith, and G. Burnstock (1985) 5-IIydroxytryptamine-like immunoreactivity in the peripheral and central nervous systems of the leech Hirudo medicinalis. Cell Tissue Res. 239: 123130.

Le Douarin, N. M. (1984) Cell migrations in embryos. Cell 38: 353 360.

Lent, C. M. (1981) Morphology of neurons containing monoamines within leech segmental ganglia. J. Exp. Zool. 216: 311-316.

Lent, C. M. (1982) Fluorescent properties of monoamine neurons following glyoxylic acid treatment of intact leech ganglia. Histochemistry $75: 77-89$.

Lent, C. M., J. Ono, K. T. Keyser, and H. J. Karten (1979) Identification of serotonin within vital-stained neurons from leech ganglia. J. Neurochem. 32: 1559-1563.

Lent, C. M., R. L. Mucller, and D. A. Haycock (1983) Chromatographic and histochemical identification of dopamine within an identified neuron in the leech nervous system. J. Neurochem. 41: 481490.

Lindvall, O., and A. Bjorklund (1974) The glyoxylic acid fluorescence histochemical method: A detailed account of the methodology for the visualization of central catecholamine neurons. Histochemistry 39 : 97-127.

Macagno, E. R. (1980) Number and distribution of neurons in leech segmental ganglia. J. Comp. Neurol. 190: 283-302.

Macagno, E. R., R. R. Stewart, and B. Zipser (1983) The expression of antigens by embryonic neurons and glia in segmental ganglia of the leech Haemopis marmorata. J. Neurosci. 3: 1746-1759.

Macagno, E. R., R. R. Stewart, and D. Spergel (1985) Differentiation and death of cells in the leech CNS. II. The unpaired medial scrotonergic neurons. Soc. Neurosci. Abstr. 11: 957.

Marsden, C. A., and G. A. Kerkut (1969) Fluorescent microscopy of the 5-HT and catecholamine-containing cells in the central nervous system of the leech Hirudo medicinalis. Comp. Biochem. Physiol. 31: 851-862.

Muller, K. J., J. G. Nicholls, and G. S. Stent, eds. (1981) Neurobiology of the Leech, Cold Spring Harbor Laboratory, Cold Spring Harbor, NY.

Nusbaum, M. P. (1986) Synaptic basis of swim initiation in the leech III. Synaptic effects of serotonin-containing interneurones (cells 21 and 61) on swim CPG neurones (cells 18 and 208). J. Exp. Biol. 122 . 303-321.

Nusbaum, M. P., and W. B. Kristan, Jr. (1986) Swim initiation in the leech by serotonin-containing interneurones, cells 21 and 61 . J. Exp. Biol. 122: 277-302.

Rakic, P. (1971) Neuron-glial relationship during granule cell migration in developing cerebellar cortex. A Golgi and electron microscopic study in Macacus rhesus. J. Comp. Neurol. 141: 238-312.

Robertson, A. M. G., and J. N. Thomson (1982) Morphology of programmed cell death in the ventral nerve cord of Caenorhabditis elegans larvae. J. Embryol. Exp. Morphol. 67: 89-100.

Rude, S. (1969) Monoamine-containing neurons in the central nervous system and peripheral nerves of the leech, Hirudo medicinalis. J. Comp. Neurol. 136: 349-371.

Rude, S., Coggeshall, R. E., and Van Orden, L. S., III (1969) Chemical and ultrastructural identification of 5-hydroxytryptamine in an identified neuron. J. Cell Biol. 41: 832-854.

Sawyer, R. T., F. LePont, D. K. Stuart, and A. P. Kramer (1981) Growth and reproduction of the giant glossiphoniid leech Haementeria ghilianii. Biol. Bull. 160: 322-331.

Schleip, W. (1936) Ontogenie der Hirundineen. In Klassen und Ordnungen des Tierreichs, H. G. Bronn, ed., Vol. 4, Div. III, Book 4, Pt. 2, pp. 1-121, Akademie Verlagsgesellschaft, Leipzig.

Shankland, M. (1987) Position-dependent cell interactions and commitments in the formation of the leech nervous system. In Current Topics in Developmental Biology, Neural Development, Part IV, R. K. Hunt, ed., Academic, New York.

Shankland, M., and D. A. Weisblat (1984) Stepwise commitment of blast cell fates during the positional specification of the $\mathrm{O}$ and $\mathrm{P}$ cell lines in the leech embryo. Dev. Biol. 106: 326-342.

Steinbusch, H. W. M., A. A. J. Verhofstad, and H. W. J. Joosten (1978) Localization of serotonin in the central nervous system by immunohistochemistry: Description of a specific and sensitive technique and some applications. Neuroscience 3: 811-819.

Stent, G. S. (1985) The role of cell lineage in development. Phil. Trans. R. Soc. London [Biol.] 312: 3-19.

Stent, G. S., D. A. Weisblat, S. S. Blair, and S. L. Zackson (1982) Cell lineage in the development of the leech nervous system. In Neuronal Development, N. C. Spitzer, ed., pp. 1-44, Plenum, New York.

Stewart, R. R., and E. R. Macagno (1984) The development of segmental differences in cell number in the CNS of the leech. Soc. Neurosci. Abstr. 10: 512 .

Stuart, A. E., A. J. Hudspeth, and Z. W. Hall (1974) Vital staining of specific monoamine-containing cells in the leech nervous system. Cell Tissue Res. 153: 55-61.

Stuart, D. K. (1981) Monoamine neurons in embryonic and adult leech. Soc. Neurosci. Abstr. 7: 2

Stuart, D. K., J. C. Glover, S. S. Blair, and D. W. Weisblat (1983) Development of leech serotonin neurons examined with serotonin antibody, cell lineage tracer, and cell killing. Soc. Neurosci. Abstr. 9: 605.

Sulston, J. E., and J. G. White (1980) Regulation and cell autonomy during postembryonic development of Caenorhabditis elegans. Dev. Biol. 78: 577-597.

Sulston, J. E., E. Schierenberg, J. G. White, and J. N. Thomson (1983) The embryonic cell lineage of the nematode Caenorhabditis elegans. Dev. Biol. 100: 64-119.

Taghert, P. H., and C. S. Goodman (1984) Cell determination and differentiation of identified serotonin-immunoreactive neurons in the grasshopper embryo. J. Neurosci. 4: 989-1000.

Torrence, S. A., and D. K. Stuart (1986) Gangliogenesis in leech embryos: Migration of neural precursor cells. J. Neurosci. 6: 2736-2746.

Truman, J. W. (1984) Cell death in invertebrate nervous systems. Annu. Rev. Neurosci. 7: 171-188.

Weisblat, D. A., and S. S. Blair (1984) Developmental interdeterminacy in embryos of the leech IIelobdella triserialis. Dev. Biol. 101: 326-335.

Weisblat, D. A., and M. Shankland (1985) Cell lineage and segmentation in the leech. Phil. Trans. R. Soc. London [Biol.] 312: 39-56.

Weisblat, D. A., R. T. Sawyer, and G. S. Stent (1978) Cell lineage analysis by intracellular injection of a tracer enzyme. Science 202: 1295-1298.

Weisblat, D. A., G. Harper, G. S. Stent, and R. T. Sawyer (1980a) Embryonic cell lineages in the nervous system of the glossiphoniid leech Helobdella triserialis. Dev. Biol. 76: 58-78.

Weisblat, D. A., S. L. Zackson, S. S. Blair, and J. D. Young (1980b) Cell lineage analysis by intracellular injection of fluorescent tracers. Science 209: 1538-1541.

Weisblat, D. A., S. Y. Kim, and G. S. Stent (1984) Embryonic origins of cclls in the leech Helobdella triserialis. Dev. Biol. 104: 65-85.

Whitman, C. O. (1878) The embryology of Clepsine. Q. J. Microsc. Sci. (N.S.) 18: 215-315.

Zackson, S. (1982) Cell clones and segmentation in leech development. Cell 31: 761-770.

Zackson, S. (1984) Cell lineage, cell-cell interaction, and segment formation in the ectoderm of a glossiphoniid leech embryo. Dev. Biol. 104: 143-160. 